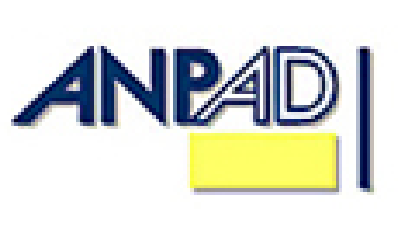

Disponível em
http://www.anpad.org.br/rac
RAC, Curitiba, v. 14, n. 3, art. 8,
pp. 532-557, Mai./Jun., 2010

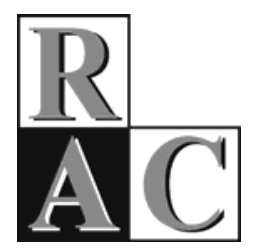

\title{
Doutores em Ciências Contábeis: Análise sob a Óptica da Teoria do Capital Humano
}

\author{
PhDs in Accounting Sciences: Analysis in Light of the Human Capital Theory
}

\begin{abstract}
Jacqueline Veneroso Alves da Cunha *
Doutora em Ciências Contábeis pela USP. Professora Adjunta na UFMG, Belo Horizonte/MG, Brasil.
\end{abstract}

Edgard Bruno Cornachione Junior

Doutor em Ciências Contábeis pela USP. Professor Associado da USP, São Paulo/SP, Brasil.

Gilberto de Andrade Martins

Doutor em Administração pela USP. Professor Titular da USP, São Paulo/SP, Brasil.

* Endereço: Jacqueline Veneroso Alves da Cunha Av. Antônio Carlos, 6627, Faculdade de Ciências Econômicas, Sala 2041, Campus Pampulha, Belo Horizonte/MG, 31270-901. E-mail: jvac@face.ufmg.br

Copyright (C 2010 RAC. Todos os direitos, inclusive de tradução, são reservados. É permitido citar parte de artigos sem autorização prévia desde que seja identificada a fonte. 


\title{
RESUMO
}

Os pressupostos da teoria do capital humano estabelecem que as pessoas se educam e que o principal efeito da educação é a mudança que ela provoca nas habilidades e conhecimentos de quem estuda. A consequência prevista é uma melhora no nível de renda, na qualidade de vida e nas oportunidades profissionais e sociais. Tendo por base esse arcabouço teórico, o propósito desta pesquisa foi identificar e analisar as avaliações e percepções dos doutores em Ciências Contábeis, titulados pela FEA/USP, sobre as influências do doutorado nos seus desenvolvimentos e nas suas responsabilidades sociais. Os achados da pesquisa confirmaram as expectativas, explicações e previsões da teoria. Na percepção dos egressos, os 19 fatores possíveis de serem alterados que lhes foram apresentados, foram substancialmente influenciados com a titulação. Os resultados evidenciam que o Doutorado em Ciências Contábeis tem encontrado sua principal clientela entre homens casados que desenvolvem suas atividades no mercado. Titulam-se, em média, aos 42 anos e, ao ingressarem, buscavam seguir ou aprimorar a carreira de pesquisador, além da obtenção de melhor nível de renda. E, nesse último ponto, alcançaram pleno êxito. Os efeitos da titulação sobre os rendimentos são bastante acentuados.

Palavras-chave: doutores; educação; teoria do capital humano.

\begin{abstract}
The assumptions pertaining to the human capital theory establish that people study, and that the main result of education is the change it grants to the abilities and knowledge of those who study. The anticipated consequence is the improvement in income, life quality and professional and social opportunities. Based on this theoretical framework, this study aims to identify and analyze the evaluations and views that holders of a PhD degree in Accounting Sciences from FEA/USP have on the influence of this degree on their social responsibilities and progress. The findings substantiate the expectations, explanations and predictions of the theory. According to graduates of this program, the 19 factors that might possibly have been altered and were presented to them, were substantially influenced by the degree. The results show that this $\mathrm{PhD}$ in Accounting Sciences has found its place mainly among married men who perform in the market. On average, they finished their degree around the age of 42 and intended to follow or enhance research skills and achievement of a higher income level when they first started. On this last point, they were completely successful. The effects of the degree on income are outstanding.
\end{abstract}

Key words: PhD degree; education; human capital theory. 


\section{INTRODUÇÃO}

O ensino superior brasileiro tem uma história curta, até mesmo quando comparada aos padrões latino-americanos. Até a Proclamação da República o objetivo atribuído ao ensino superior era assegurar um diploma profissional que desse o direito de ocupar postos privilegiados em um mercado de trabalho bastante restrito, além de garantir privilégio social.

Apesar do atraso, Menezes-Filho (2001) relata que os retornos econômicos, em termos salariais no Brasil, estão entre os mais altos do mundo, o que é atribuído ao próprio processo de expansão educacional, que privilegia a poucos, e a aspectos socioculturais. Os indivíduos com 15 a 16 anos de estudo, que representam o superior completo, têm um rendimento salarial médio quase doze vezes maior do que aqueles sem escolaridade. Quando o indivíduo tem o mestrado, a diferença sobe para dezesseis vezes.

No entanto, conforme Cave e Weale (1996), o benefício financeiro trazido pelo ensino superior, apesar de importante, não é o único, há vários outros. Os autores relatam que, numa comparação internacional realizada pela Organisation for Economic Co-operation and Development [OECD] em 1989, foram encontradas evidências de que o desemprego para graduados é mais baixo do que para outros tipos de trabalhadores sem a graduação. No Reino Unido, em 1987, a propensão ao desemprego para uma pessoa que houvesse abandonado a escola era quatro vezes maior do que para um graduado.

No Brasil, o número de profissionais qualificados cresceu muito nos últimos anos. De acordo com as estatísticas elaboradas pelo Instituto Nacional de Estudos e Pesquisas Educacionais Anísio Teixeira [INEP] (2004), o número de cursos no ensino superior cresceu mais de 375\%, passando de 3.923, em 1985, para 18.644 em 2004. O total de concluintes aumentou mais de $175 \%$ de 1980 para 2004. Em 1980, formavam-se 226.423 alunos e, em 2004, foram 626.617 (em 1963 esse número não passava de 19.049). Nesse mesmo período, a população do país aumentou pouco mais de 50\% (de 119.002 .706 em 1980 para mais de 180.000 .000 em 2004) e o PIB cresceu mais de $150 \%$.

Quando são avaliados os dados da Coordenação de Aperfeiçoamento de Pessoal de Nível Superior [CAPES], instituição responsável pelo acompanhamento e avaliação dos Cursos de Pós-Graduação Stricto Sensu brasileiros, também se comprova o notável crescimento desse segmento no Brasil. De 1976, ano em que teve início o processo de avaliação dos Cursos de Pós-Graduação pela Capes, a 2004, os cursos recomendados passaram de um total de 673, (desses, 183 doutorados) para 2.993 (sendo 1.034 doutorados). O país que, em 1987, contava com 7.914 alunos matriculados nos cursos de doutorado passou, em 2003, a contar com 40.213. O número de titulados (mestrado e doutorado) saiu de 7.039 em 1990 para 35.724 em 2003. Nesse mesmo período, o número de doutores subiu de 1.302 para 8.094 (Capes, 2004).

A área de Pós-Graduação Stricto Sensu em Ciências Contábeis, no entanto, não se desenvolveu na mesma proporção observada nas outras ciências. Em 2009, são 18 os programas de Pós-Graduação Stricto Sensu, apesar dos mais de 1.000 cursos de graduação em Ciências Contábeis, a grande maioria deles em cursos noturnos e em mãos de escolas particulares e cursos de Pós-Graduação Lato Sensu intuitivamente em números crescentes, visto que a Capes não possui cadastro completo dos cursos reconhecidos nesse nível. O Curso de Doutorado em Ciências Contábeis com concentração em Controladoria e Contabilidade da USP foi o único no país por 30 anos. Iniciou-se em 1978 e titulou, até 31 de dezembro de 2008, 186 doutores. Se todos os doutores titulados até 2003 (em número de 135) estivessem alocados nos Cursos de Graduação em Ciências Contábeis existentes na mesma data (701 cursos), ter-se-ia uma taxa de 0,19 doutores por curso. Tomados o número de alunos matriculados nos cursos de graduação em 2004 (127.468) e os 142 doutores titulados até então, obtémse um índice de 0,001 doutores por aluno, ou 897 alunos por doutor, isso se estivessem todos na ativa e na área acadêmica. No ano de 2008, foram credenciados mais 2 programas de doutoramento: o doutorado em Ciências Contábeis do Programa Multiinstitucional UNB/UFPB/UFRN e o doutorado em Ciências Contábeis e Administração da Fundação Universidade Regional de Blumenau [FURB], 
ambos com primeira turma iniciada nesse mesmo ano. Apenas para fins de comparação, conforme Hasselback (2007), nos EUA são 91 os programas de doutorado em Contabilidade, ativos, em escolas acreditadas pela Association to Advance Collegiate Schools of Business [AACSB].

Nesse contexto, pesquisar as alterações ocorridas na vida dos doutores em Ciências Contábeis titulados pela FEA/USP direciona o objetivo deste estudo: identificar e analisar as avaliações e percepções dos doutores em Ciências Contábeis titulados pela FEA/USP sobre as influências do doutorado nos seus desenvolvimentos e responsabilidades sociais.

Os resultados deste estudo poderão servir de fonte de consulta para futuros aspirantes ao título e para instituições de fomento à pesquisa na sua alocação de recursos, principalmente nesse momento em que se cogita a implantação de outros programas de doutoramento em Contabilidade no país, após 30 anos de hegemonia do doutorado da USP. No âmbito da universidade, conhecer o desempenho profissional dos egressos do doutorado da FEA/USP permitirá ao Departamento de Contabilidade e Atuária uma compreensão do seu próprio papel e as contribuições do programa para os indivíduos e a sociedade.

\section{Plataforma Té́rica}

\section{A Teoria do Capital Humano}

Adam Smith já sabia da influência que a escolaridade exercia sobre o mercado de trabalho, quando afirmava que a diferença entre um filósofo e um carregador de malas parecia surgir não tanto da natureza, mas de hábitos, costumes e educação. Foi ele o introdutor da noção do ser humano como capital no seu clássico Riqueza das nações - Wealth of nations (1776) e, também, quem formulou as bases do que mais tarde se tornaria a ciência do capital humano. Outros, como Alfred Marshall e Irving Fisher, mantiveram a idéia viva (Baptiste, 2001; Fitzsimons, 1999; Ioschpe, 2004; Schuller \& Field, 1998; Schultz, 1961; Stamatakis \& Petrakis, 2005; Stuart, Dattero, \& Quan, 2004; Walsh, 1935).

O termo capital humano refere-se ao conjunto de capacidades produtivas dos seres humanos formadas pelos conhecimentos, atitudes e habilidades e que geram resultados em uma economia (Baptiste, 2001; Becker, 1962; Blaug, 1975). A característica preponderante do capital humano é que ele parte do homem. Configura-se como capital, porque é fonte de satisfações futuras, ou de futuros rendimentos, ou ambas as coisas. É humano, porque se torna parte do homem. Como os homens são livres, o capital humano não é um ativo negociável que se adquire no mercado, no sentido de que possa ser vendido. Entretanto pode ser adquirido por intermédio de um investimento no próprio indivíduo (Schultz, 1973). A característica diferenciadora entre o capital físico e o capital humano é que o poder para utilizá-lo no capital humano pertence ao indivíduo que o incorpora, independentemente de qual foi a fonte financiadora do investimento (Johnson, 1964) e a comum é que ambos estão sujeitos à obsolescência, devendo sofrer manutenção (Schultz, 1973).

Schultz (1960) propõe tratar a educação como forma de investimento no homem, visto que ela se torna parte da pessoa que a recebe. Portanto, é uma forma de capital humano. Sua proposta baseou-se na hipótese de que alguns aumentos importantes no rendimento nacional americano seriam consequência das adições dessa forma de capital.

No prefácio de seu livro - O capital humano (1973), Schultz declarou que:

Na Universidade de Chicago, a partir de fins da década de 1940, comecei a procurar uma explicação mais completa e a verificar o papel das capacidades adquiridas dos agentes humanos como uma fonte mais importante dos ganhos de produtividade não explicados. Essas capacidades adquiridas obviamente não eram gratuitas. Recursos escassos estavam sendo destinados à aquisição de tais capacidades; e, desta forma, o estágio analítico voltou-se para os investimentos feitos no homem. 
Investimento no homem significava que o conceito tradicional de capital tinha de ser ampliado, a fim de abarcar a realidade relativa ao capital humano.

Entretanto só na década de 1960, com o surgimento da Teoria do Capital Humano [TCH] pelas mãos de Theodore W. Schultz, Gary S. Becker, ganhadores do prêmio Nobel de Economia em 1979 e 1992, respectivamente, e Jacob Mincer, começou-se a atribuir valor ao fator humano pela sua capacidade de gerar serviços (Blaug, 1976; Cunha, 2007; Ioschpe, 2004).

A chave da teoria do capital humano é o conceito de que a aquisição de mais conhecimentos e habilidades aumenta o valor do capital humano das pessoas, aumentando sua empregabilidade, produtividade e rendimento potencial. Consequentemente, o investimento em educação leva a um aumento de renda futura, além de ocupar uma posição destacada no progresso das sociedades na forma de bem-estar social e inovação tecnológica.

Diversos estudos comprovaram a eficiência da escolaridade em proporcionar benefícios aos indivíduos. Psacharopoulos e Patrinos (2002), revisando e apresentando as últimas estimativas e padrões de taxas médias de retorno à escolaridade em diversos países do mundo, constataram que as mais altas são as da África Subsaariana (37,6\%, 24,6\% e 27,8\% para o ensino primário, secundário e superior, respectivamente) e as mais baixas foram as pertencentes aos países membros da OCDE $(13,4 \%, 11,3 \%$ e $11,6 \%$, na mesma ordem). Sobel (1978) salientou que as taxas de retorno por profissão variam de país a país; mas, em geral, as maiores podem ser obtidas em Odontologia, Medicina, Engenharia, Administração de Negócios e Economia. Outros comprovaram o impacto da escolaridade na vida dos envolvidos (Baruch \& Peiperl, 2000; Dugan, Grady, Payn, \& Johnson, 1999; Hunton, Stone, \& Wier, 2005; Newell, Langsam, \& Kreuze, 1996). Alguns autores coletaram evidências de que existe um ganho para a sociedade, conhecido como externalidades, provocado pela educação, que vai além do somatório dos prêmios de salários individuais, ou seja, a taxa de retorno social para a educação difere positivamente da taxa de retorno privada. Dentre eles Farrel e Fuchs (1982), Moretti (2002), Lochner e Moretti (2001), Rauch (1993), Psacharopoulos e Patrinos (2002).

A realidade brasileira reafirma as constatações dos estudos estrangeiros. Altas taxas de retorno (Lam \& Levison, 1990; Langoni, 1973; Ramos, 1991; Senna, 1976; Tannen, 1991). Diferenças salariais entre trabalhadores que não são explicadas apenas por diferenças nos seus atributos produtivos (Gonzaga \& Soares, 1999). O impacto de diferentes cursos superiores no desempenho trabalhista, observado a posteriori (Centro de Políticas Sociais da Fundação Getúlio Vargas [CPS/FGV] Coordenado por Marcelo Néri). O desempenho no mercado de trabalho das pessoas com instrução superior (Fernandes \& Narita, 2001) e as influências da escolaridade na carreira (Frezatti \& Kassai, 2003; Machado, 2003).

A teoria do capital humano estabelece, portanto, uma explicação importante para a atribuição da educação no aumento da produtividade e como o principal fator de explicação para os diferenciais de renda observados no mercado de trabalho. As evidências empíricas comprovam que ela tende a ser mais importante para países subdesenvolvidos do que para os desenvolvidos, em virtude da má distribuição da educação entre a força de trabalho. Um paradigma da teoria do capital humano é que as pessoas investiriam em si mesmas (saúde, aquisição de informações, educação, etc.), visando a retornos a futuros, mesmo que estes ganhos não representassem aspectos pecuniários; ou os indivíduos poderiam adquirir mais escolaridade simplesmente por satisfação pessoal. A escolaridade geraria habilidades cognitivas que representariam enorme valor para o próprio sujeito, para o mercado e para a comunidade, que retribuiriam com maior remuneração, mobilidade, diferenciação e estabilidade profissional, status, prestígio, respeitabilidade e reconhecimento, dentre outros. Elevações nos níveis de capital humano dos indivíduos, no entanto, não geram apenas significativos aumentos na produtividade e nos salários. Elevam também a competitividade das empresas, o bem-estar dos empregados e a vida da comunidade como um todo. Além disso, influenciariam os níveis de responsabilidade social, conforme evidenciado em pesquisas que comprovaram que a educação repercute na formação de líderes, eleitorado mais capacitado, consciência social, doação de tempo e dinheiro à caridade (Blaug, 1965; Haveman \& Wolfe, 1984; Ioschpe, 2004). 


\section{ABORDAGEM METODOLÓGICA}

\section{Caracterização do Estudo}

Em função dos propósitos deste estudo foi utilizada uma abordagem de natureza empírico-analítica que, segundo descreveu Martins (2000, p. 30),

São abordagens que apresentam em comum a utilização de técnicas de coleta, tratamento e análise de dados marcadamente quantitativas. Privilegiam estudos práticos. Suas propostas têm caráter técnico, restaurador e incrementalista. Tem forte relação causal entre as variáveis. A validação da prova científica é obtida através de testes de instrumentos, graus de significância e sistematização das definições operacionais.

A estratégia de pesquisa usada para atender aos objetivos estabelecidos e responder à questão de pesquisa foi a descritiva. Conforme Gall, Gall e Borg (2007), esse tipo de estudo envolve a descrição de um fenômeno social ou natural: sua forma, estrutura, atividade, mudanças e relacionamentos ao longo do tempo, dentre outros. Além da descrição das características de determinada população ou fenômeno, esse tipo de pesquisa tem como principal objetivo estabelecer relações entre variáveis e fatos (Martins, 2000).

Com base na tipologia e objetivos da pesquisa, optou-se pelo uso do questionário como instrumento de coleta de dados primários; são conhecidas as suas vantagens e também suas limitações.

\section{Estruturação do Questionário}

O questionário foi estruturado com os seguintes blocos: (a) Identificação; (b) Percurso acadêmico; (c) Atividade atual; (d) Doutorado e trabalho; (e) Influências do doutorado; (f) Atividade no ingresso no doutorado. Além dos seis blocos, foi deixado espaço adicional para que os respondentes pudessem registrar outros comentários que julgassem necessários. No bloco sobre as influências do doutorado foram utilizados os fatores que são influenciados pelo título de doutor, levantados e caracterizados por Cunha (2007), em utilizar a técnica Delphi.

A qualidade do instrumento de coleta de dados foi determinada por meio de 2 sessões de pré-teste. Após a realização do pré-teste, optou-se por realizar a aplicação do questionário por meio eletrônico, considerada a forma mais segura, interativa, agradável e rápida, tanto para os respondentes quanto para os pesquisadores. Avaliados, principalmente, interatividade, segurança e custo/benefício, optou-se pelos serviços da Vroman Systems, Incorporation, uma empresa privada, baseada em Chicago, Illinois, responsável pelo desenvolvimento do FormSite.com, em 1998. O questionário, então, foi construído via web, gerando um link que mais tarde seria remetido aos pesquisados para que pudessem acessá-lo. Foi solicitado aos participantes do pré-teste que avaliassem a versão eletrônica do questionário.

Mesmo consideradas todas as dificuldades de localização dos egressos, consideram-se altamente satisfatórios os resultados. Foram localizados 150 egressos, outros 9 já haviam falecido.

Foram enviados 150 e-mails, com uma carta de apresentação dos pesquisadores, garantindo privacidade e explicitando os objetivos e esclarecimentos da pesquisa e o link para que pudessem acessar o questionário eletrônico. Ressalte-se que 3 pesquisados optaram por responder ao questionário em formato não eletrônico. Um deles solicitou que o questionário lhe fosse enviado via correio, mesma forma utilizada para devolvê-lo. Os outros dois imprimiram o questionário eletrônico, responderam e o entregaram pessoalmente.

O procedimento de coleta de dados primários, por meio do questionário, iniciou-se em 21/03/2007 e foi encerrado em 21/05/2007, data considerada como segura para que o processo de conclusão do trabalho fosse realizado. No dia 28/05/2007, foi enviado um e-mail de agradecimento pela participação a todos os respondentes. 


\section{ANÁlISE dOS RESULTADOS}

Dos 150 questionários enviados, foram recebidas 132 respostas, representando 88\% de respondentes. Antes de iniciado o processo de análise, procedeu-se à crítica e consistência dos dados. No processamento das questões sobre identificação e percurso acadêmico, alguns dados de natureza demográfica, que deixaram de ser preenchidos pelos respondentes, foram completados utilizando seus currículos Lattes. Durante o processo de crítica e consistência também foram observados aspectos quanto a anos de término de graduação e início de mestrado, além do término deste e início de doutoramento. As inconsistências encontradas também foram corrigidas, utilizando os currículos Lattes. Após o processo de crítica e consistência, os dados foram transferidos para o SPSS ${ }^{\circledR} 13.0$ para a realização das análises.

\section{Estatísticas Descritivas}

\section{Identificação}

Os doutores em Ciências Contábeis estão concentrados em poucas IES. Dos 132 respondentes, 48,5\% estão vinculados a um grupo de 10 IES: FEA/USP - São Paulo (19,8\%), FEA/USP - Ribeirão Preto (5,3\%), PUC - São Paulo (4,5\%), Fecap, Fucape, Furb e UNB (3,0\% cada), UFPE, UFC e UFRJ (2,3\% cada). As instituições não acadêmicas mais frequentes foram o Unibanco e o Banco Itaú, com $1,5 \%$ dos doutores cada uma. Nos Ministérios Federais se encontram 3,2\% dos respondentes. São Paulo é a cidade com maior concentração de doutores, 43,9\%, seguida por Brasília com 6,8\%. O Estado de São Paulo sozinho mantém 57,7\% de todos os respondentes que se encontram no país (130 representando 98,5\%). Os outros 40,8\% respondentes estão distribuídos em 12 outros Estados da Federação: DF, RJ, PR, MG, RS, SC, ES, BA, CE, PE, PB e RN, concentrando os titulados na região Sudeste $(71,5 \%)$ acompanhada das regiões Sul $(11,5 \%)$ e Nordeste $(10,0 \%)$, respectivamente. Ressalte-se que, ao ingressarem no doutorado, eram oriundos, principalmente, do Estado de São Paulo (65,1\%). A segunda principal origem era o Estado do Rio de Janeiro (6,3\%). Dois doutores não se encontram mais no país. Retornaram a seus países de origem, um deles Assunção no Paraguai e o outro em Cali na Colômbia. A idade média dos titulados era de 51 anos, com desvio padrão de 10,47 anos. O doutor mais idoso possuía 79 anos (nascimento 1928) e o mais novo 28 anos (nascimento 1979). O estado civil mais comum entre os respondentes é casado $(71,2 \%)$, seguido por solteiro $(10,6 \%)$.

A hegemonia masculina é muito forte entre os doutores em Ciências Contábeis. Dos 132 respondentes, $84,8 \%$ pertencem ao sexo masculino e apenas $15,2 \%$ ao feminino. Num estudo realizado por Stirati e Cesaratto (1995) sobre o doutorado na Itália, os autores relataram que entre os beneficiários de doutorados italianos a participação feminina está entre as mais altas do mundo, 43,0\% (base 1990/1991). Nos EUA, as mulheres representavam 36,0\% dos participantes (base 1989), no Reino Unido 24,0\% (base 1990), na Alemanha 20,0\% (base 1982) e na Suécia 18,0\% (base 1980/1981). No estudo de Carcello, Hermanson, Hermanson e Turner (1994), envolvendo apenas estudantes da maioria dos programas de doutorado em Contabilidade americanos, a proporção de mulheres foi superior à participação geral, alcançando o percentual de 41,0\%. Em termos de Brasil, o percentual de doutores em Ciências Contábeis pertencentes ao sexo feminino é inferior àquele encontrado por Spagnolo e Günther (1986), num estudo abrangendo oito áreas de estudo. A proporcionalidade encontrada por esses autores nas oito áreas abrangidas pelo estudo, de uma maneira geral, foi de $20,3 \%$ de doutores do sexo feminino e 79,7\% do masculino. Se comparado ao estudo organizado por Velloso (2002), envolvendo as áreas de Administração, Agronomia, Bioquímica, Clínica Médica, Engenharia Civil, Engenharia Elétrica, Física, Química e Sociologia, esse percentual só fica acima do percentual de doutores do sexo feminino em Engenharia Elétrica, 9,5\%. 


\section{Percurso Acadêmico}

Doutores em Ciências Contábeis terminam sua graduação, em média, aos 24,4 anos, com desvio padrão de 3,26 anos. Mais velhos que seus colegas, os doutores em Química, 23,7 anos (Braga \& Azevedo, 2002), Engenharia Elétrica, entre 23 e 24 anos (Ivo \& Carvalho, 2002) e Bioquímica, pouco mais de 23 anos (Braga, 2002). Na análise realizada por Matos, Balbachevsky, Sampaio e Velloso (2002), a idade média da conclusão da graduação dos doutores em Administração é similar, entre 24 e 25 anos. O prazo médio de conclusão da graduação foi de 4 anos, com mínimo de 3 e máximo de 9 anos.

Em sua maioria, os doutores em Ciências Contábeis são provenientes da mesma área de graduação, 55,3\% cursaram Ciências Contábeis como primeira graduação; 22,0\% Administração; 14,4\% Economia, e o restante distribuídos entre Direito, Engenharia e Matemática. Cerca de $25,0 \%$ dos respondentes informaram possuir mais de um curso de graduação. Dos 58 titulados que não possuem Ciências Contábeis como primeira graduação, 18 a possuem como segunda graduação. Portanto, 70,0\% dos respondentes possuem o doutorado na mesma área de sua graduação.

O tempo médio transcorrido entre o final da graduação e o início do mestrado foi de 6 anos, com desvio padrão de 5,54 anos, dispersão elevada, demonstrando trajetórias bem diferenciadas. Quando comparado ao estudo organizado por Velloso (2002), percebe-se que o número de anos está entre aquele encontrado para os cursos de Sociologia e Agronomia, cujo tempo médio estava entre 4,5 e 5 anos; para os cursos de Clínica Médica e Administração, com tempo médio da ordem de 7 anos. Nos cursos de Engenharia Civil, Engenharia Elétrica, Química, Bioquímica e Física, o tempo médio variou de 1,5 a 3,6 anos, sendo significativamente diferente do tempo encontrado para o Doutorado em Ciências Contábeis.

O prazo médio para a conclusão do mestrado foi de 3 anos e 9 meses. Dos 132 respondentes, 7 (5,3\%) não informaram a data de início e término do mestrado, possibilitando inferir que cursaram o doutorado direto, já que existe essa possibilidade no doutoramento da FEA/USP. Cabe observar o domínio do modelo sequencial mestrado/doutorado que, mesmo não sendo obrigatório no país, está presente na área de Ciências Contábeis, assim como em outras. Administração, por exemplo, como constatado por Matos et al. (2002). O curso de mestrado da maioria dos respondentes (76,5\%) também foi na área de Ciências Contábeis. Dos 101 titulados com o mestrado na área de Ciências Contábeis, 85,1\% o cursaram no Programa de Pós-Graduação em Ciências Contábeis da FEA/USP. Constata-se, portanto, que os doutores em Ciências Contábeis, em sua maioria, possuem mestrado e graduação na mesma área de conhecimento. Mais uma vez se confirma o resultado encontrado por Velloso e Velho (2001) em mais de 60,0\% dos pesquisados, tanto com relação à área de conhecimento do mestrado e graduação quanto à instituição do mestrado ser a mesma do doutorado. A Tabela 1 apresenta a origem dos títulos dos 101 doutores que também se titularam como mestres na área contábil.

Tabela 1

\section{Instituição do Título de Mestrado na Área Contábil}

\begin{tabular}{ccc}
\hline Instituição & Frequência & Percentual \\
\hline FEA/USP & 86 & 85,1 \\
FGV/RJ/ISEC & 6 & 6,0 \\
PUC/SP & 7 & 6,9 \\
UERJ & 2 & 2,0 \\
Total & 101 & 100,0 \\
\hline
\end{tabular}

O tempo médio transcorrido entre o término do mestrado e o início do doutorado, por sua vez, é inferior àquele observado entre a graduação e o mestrado, em torno de 3 anos e 2 meses. No entanto o 
prazo para a conclusão do doutorado é superior ao do mestrado. Em média, 4 anos e 5 meses com desvio padrão de 1,57 anos. Em uma pesquisa realizada por Carcello et al. (1994), envolvendo 346 estudantes de cursos de doutorado em Contabilidade da maioria dos programas americanos, o prazo médio para a conclusão do curso esteve muito próximo da média brasileira, sendo de 4 anos e 6 meses. Mangematin (2000) constatou que os doutores em Ciências de Engenharia, titulados na Universidade de Grenoble, França, no período de 1984 a 1996, levaram cerca de 3 anos e 4 meses para concluir seu curso.

A idade média dos respondentes ao término do doutorado situava-se em torno de 42 anos, bastante elevada, mas perfeitamente compatível com outras áreas do conhecimento, no Brasil. Carcello et al. (1994) relataram que a idade média dos estudantes de doutorado em Contabilidade americanos é de 34 anos, com prazo médio de conclusão de 4 anos e 6 meses, o que resultará em doutores com idade bem abaixo do padrão encontrado neste estudo. Segundo Stirati e Cesaratto (1995), a idade média de ingresso no doutorado na Itália (em todas as áreas do conhecimento) é de 28 anos, levando em torno de 5 anos para sua conclusão, o que equivale a 33 anos a idade média de seu término, também abaixo do padrão nacional.

O título de doutor parece ter caráter terminal nos estudos de Ciências Contábeis. Apenas 14 doutores $(10,6 \%)$ informaram ter realizado pós-doutoramento. Os EUA foram o país escolhido pela maioria deles (9), seguidos pela França e Brasil (2 em cada um dos países) e Nova Zelândia (apenas 1). Essa mesma constatação foi feita por Matos et al. (2002) com os doutores em Administração. A Tabela 2 apresenta as principais estatísticas relativas à trajetória acadêmica dos respondentes.

Tabela 2

Trajetória Acadêmica dos Doutores em Ciências Contábeis

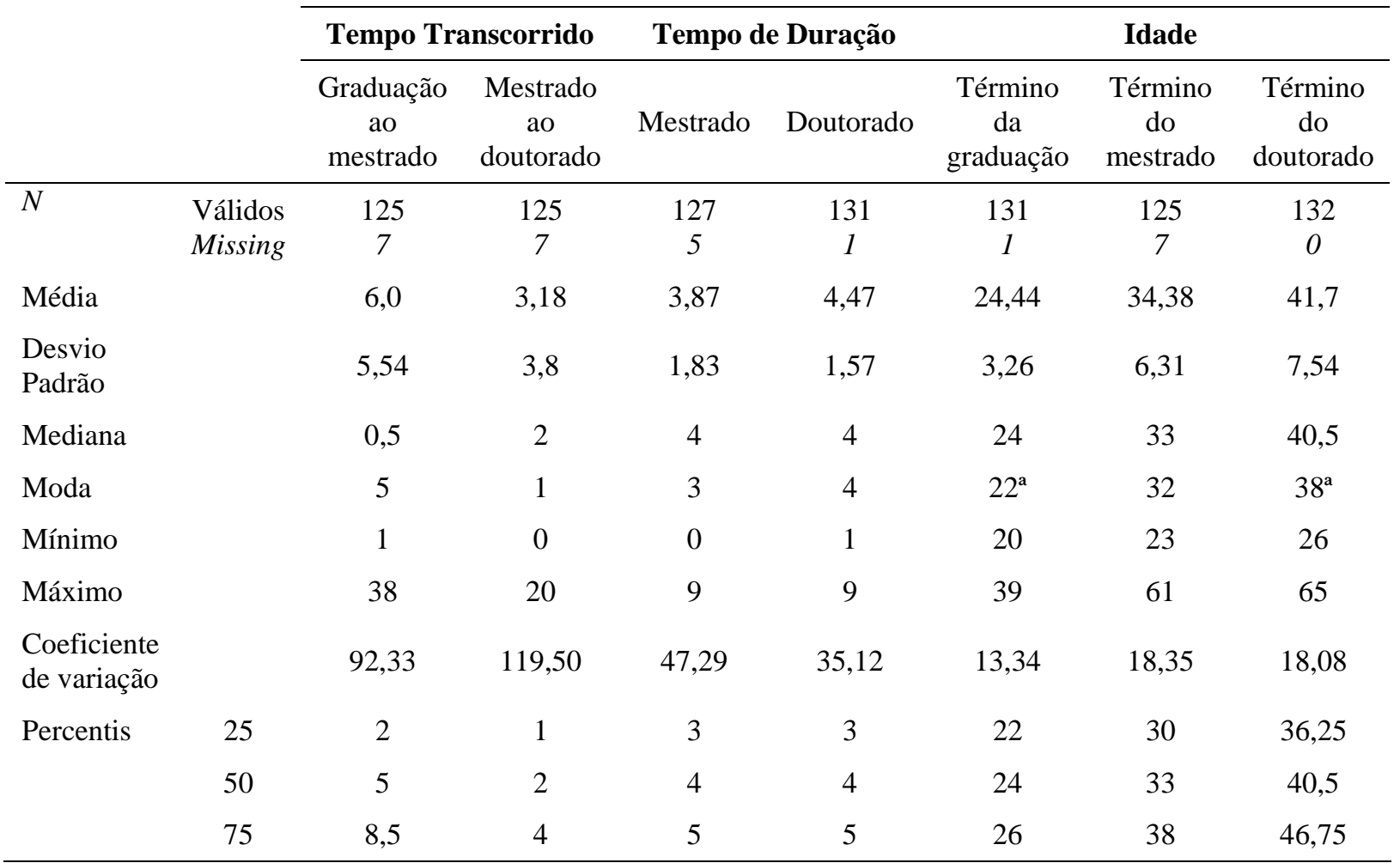

Nota. ${ }^{a}$ Existem múltiplas modas. Esse é o menor valor. 


\section{Atividade Atual dos Doutores em Ciências Contábeis e no Ingresso no Doutorado}

Porcentagem expressiva de respondentes (68,9\%) declarou que sua principal atividade remunerada, atualmente, está ligada à academia; mais da metade dos doutores $(51,1 \%)$ atuam como empregados no setor público. Mesmo assim, pode-se observar uma proporção não desprezível de doutores atuando no mercado, muito provavelmente em função da área de Ciências Contábeis ser considerada de formação com ênfase mais profissional. Conforme observado por Sampaio e Velloso (2002), na área em que a formação tem ênfase profissional, coerentemente são maiores as proporções de doutores em empresas do que nas áreas em que a formação tem ênfase acadêmica. Outros autores encontraram essa mesma tendência em seus estudos (Matos et al., 2002; Spagnolo \& Günther, 1986). Quando solicitados a informar se eram docentes no ensino superior na principal atividade remunerada, $66,2 \%$ responderam que sim. Como a qualificação para a docência universitária constitui-se numa das finalidades da pósgraduação, os resultados da pesquisa sugerem que, pelo menos no que diz respeito à área de Ciências Contábeis, essa política vem alcançando êxito. A Tabela 3 apresenta um resumo da atividade atual desempenhada pelos doutores.

Tabela 3

Atividade Atual dos Doutores em Ciências Contábeis

\begin{tabular}{|c|c|c|c|c|c|c|}
\hline & \multicolumn{2}{|c|}{ Academia } & \multicolumn{2}{|c|}{ Mercado } & \multicolumn{2}{|c|}{ Total } \\
\hline & $\mathbf{N}_{1}$ & $\%$ & $\mathbf{N}_{2}$ & $\%$ & $\mathbf{N}$ & $\%$ \\
\hline Principal atividade remunerada & 91 & 68,9 & 41 & 31,1 & 132 & 100 \\
\hline Total & 91 & 68,9 & 41 & 31,1 & 132 & 100 \\
\hline Missing & 0 & & 0 & & 0 & \\
\hline \multicolumn{7}{|l|}{ Situação } \\
\hline Empregado setor público & 57 & 63,3 & 11 & 26,8 & 67 & 51,1 \\
\hline Empregado setor privado & 25 & 27,8 & 7 & 17,1 & 32 & 24,4 \\
\hline Autônomo, profissional liberal, consultor & & & 11 & 26,8 & 11 & 8,4 \\
\hline Proprietário ou sócio proprietário & 3 & 3,3 & 9 & 22 & 12 & 9,2 \\
\hline Outros & 5 & 5,6 & 3 & 7,3 & 9 & 6,9 \\
\hline Total & 90 & 100 & 41 & 100 & 131 & 100 \\
\hline Missing & 1 & & 0 & & 1 & \\
\hline \multicolumn{7}{|c|}{ Docência em IES na principal atividade remunerada } \\
\hline Não & 4 & 4,4 & 40 & 100 & 44 & 33,8 \\
\hline Sim & 86 & 95,6 & & & 86 & 66,2 \\
\hline Total & 90 & 100 & 40 & 100 & 130 & 100 \\
\hline Missing & 1 & & 1 & & 2 & \\
\hline
\end{tabular}

Dos doutores envolvidos com docência no ensino superior na principal atividade remunerada, 66,7\% desempenham a função em IES públicas, 85,0\% em universidades, 73,9\% sob regime de trabalho de dedicação exclusiva à docência e pesquisa; $94,2 \%$ assinalaram sim, quando perguntados se suas atividades atuais envolviam pesquisa.

Ao ingressarem no doutorado, na situação de empregados do setor público e do privado em sua maioria, mais da metade dos respondentes mantinham sua principal atividade remunerada ligada ao mercado (51,5\%). Percebe-se nitidamente uma migração dos doutores para a academia, comparando- 
se com os $31,1 \%$ que declararam ter sua principal atividade remunerada atualmente vinculada ao mercado. A sustentação se dá com a realização do teste de significância para igualdade entre duas proporções populacionais. Como $Z_{c a l} 3,37>2$, rejeita-se a hipótese da igualdade entre as proporções, concluindo-se em nível de significância de $4,5 \%$ que a proporção de doutores que se encontrava no mercado na época do ingresso no doutorado é significativamente diferente daquela que se encontra no mercado hoje.

A docência e a pesquisa parecem ser o destino dos titulados. O doutorado orienta os titulados para a docência e pesquisa. O teste de significância também sustenta essa afirmação. Em nível de significância de 4,5\%, sustenta-se que o número de egressos que exercia a docência em IES como principal atividade remunerada, na ocasião do ingresso no doutoramento é significativamente diferente daquele que exerce a docência em IES como principal atividade remunerada atualmente $\left(Z_{c a l}-7,94<-\right.$ 2). Percebe-se, assim, que o término do doutorado funciona como reorientador de opções profissionais. Nas Tabelas 4 e 5, podem-se comparar as atividades dos ingressantes e as que desenvolvem atualmente.

Tabela 4

Trajetória do Ingresso à Situação de Trabalho Atual dos Doutores em Ciências Contábeis

\begin{tabular}{|c|c|c|c|c|c|c|c|c|c|c|c|c|}
\hline & \multicolumn{6}{|c|}{ No Ingresso } & \multicolumn{6}{|c|}{ Atual } \\
\hline & \multicolumn{2}{|c|}{ Academia } & \multicolumn{2}{|c|}{ Mercado } & \multicolumn{2}{|c|}{ Total } & \multicolumn{2}{|c|}{ Academia } & \multicolumn{2}{|c|}{ Mercado } & \multicolumn{2}{|c|}{ Total } \\
\hline & Freq. & $\%$ & Freq. & $\%$ & Freq. & $\%$ & Freq. & $\%$ & Freq. & $\%$ & Freq. & $\%$ \\
\hline Principal atividade remunerada & 64 & 48,5 & 68 & 51,5 & 132 & 100 & 91 & 68,9 & 41 & 31,1 & 132 & 100 \\
\hline Total & 64 & 48,5 & 0 & 51,5 & 132 & 100 & 91 & 68,9 & 41 & 31,1 & 132 & 100 \\
\hline Missing & 0 & & & & 0 & & 0 & & 0 & & 0 & \\
\hline \multicolumn{13}{|l|}{ Situação } \\
\hline Empregado setor público & 44 & 69,8 & 16 & 23,5 & 60 & 45,8 & 57 & 63,3 & 11 & 26,8 & 68 & 51,1 \\
\hline Empregado setor privado & 16 & 25,4 & 25 & 36,8 & 41 & 31,3 & 25 & 27,8 & 7 & 17,1 & 32 & 24,4 \\
\hline Autônomo, profissional liberal, consultor & 2 & 3,2 & 9 & 13,2 & 11 & 8,5 & & & 11 & 26,8 & 11 & 8,4 \\
\hline Proprietário ou sócio proprietário & & - & 12 & 17,7 & 12 & 9,2 & 3 & 3,3 & 9 & 22,0 & 12 & 9,2 \\
\hline Outros & 1 & 1,6 & 6 & 8,8 & 7 & 5,2 & 5 & 5,6 & 3 & 7,3 & 8 & 6,9 \\
\hline Total & 63 & 100 & 68 & 100 & 131 & 100 & 90 & 100 & 41 & 100 & 131 & 100 \\
\hline Missing & 1 & & 0 & & 1 & & 1 & & 0 & & 1 & \\
\hline \multicolumn{13}{|l|}{$\begin{array}{l}\text { Docência em IES na principal atividade } \\
\text { remunerada }\end{array}$} \\
\hline Não & 4 & 6,3 & 56 & 100 & 60 & 50 & 4 & 4,4 & 40 & 100 & 44 & 33,8 \\
\hline Sim & 60 & 93 & & - & 60 & 50 & 86 & 95,6 & & - & 86 & 66,2 \\
\hline Total & 64 & 7 & 56 & 100 & 120 & 100 & 90 & 100 & 40 & 100 & 130 & 100 \\
\hline Missing & 0 & 100 & 12 & & 12 & & 1 & & 1 & & 2 & \\
\hline
\end{tabular}


Tabela 5

Característica das IES onde Lecionam e Lecionavam os Doutores em Ciências Contábeis Trajetória

\begin{tabular}{|c|c|c|c|c|}
\hline & \multicolumn{2}{|c|}{ No Ingresso } & \multicolumn{2}{|c|}{ Atual } \\
\hline & $\mathbf{N}_{1}$ & $\%$ & $\mathbf{N}_{2}$ & $\%$ \\
\hline \multicolumn{5}{|l|}{ Natureza da IES } \\
\hline Pública & 17 & 28,3 & 58 & 66,7 \\
\hline Privada & 43 & 71,7 & 29 & 33,3 \\
\hline Total & 60 & 100 & 87 & 100 \\
\hline Missing & 4 & & 4 & \\
\hline \multicolumn{5}{|l|}{ Tipo de IES } \\
\hline Universidade & 54 & 90,0 & 74 & 85,0 \\
\hline Centro Universitário & 2 & 3,3 & 5 & 5,8 \\
\hline Faculdade & 1 & 1,7 & 4 & 4,6 \\
\hline \multicolumn{5}{|l|}{ CEFET } \\
\hline Outra & 3 & 5,0 & 4 & 4,6 \\
\hline Total & 60 & 100 & 87 & 100 \\
\hline Missing & 4 & & 4 & \\
\hline \multicolumn{5}{|l|}{ Regime de Trabalho } \\
\hline Dedicação exclusiva a docência e pesquisa & 29 & 50,9 & 62 & 73,9 \\
\hline Tempo integral a docência & 13 & 22,8 & 10 & 11,9 \\
\hline Hora/aula & 10 & 17,5 & 6 & 7,1 \\
\hline Outra & 5 & 8,8 & 6 & 7,1 \\
\hline Total & 57 & 100 & 84 & 100 \\
\hline Missing & 7 & & 7 & \\
\hline \multicolumn{5}{|l|}{ Atividades envolvem pesquisa } \\
\hline Não & 23 & 39,0 & 5 & 5,8 \\
\hline Sim & 36 & 61,0 & 81 & 94,2 \\
\hline Total & 59 & 100 & 86 & 100 \\
\hline Missing & 5 & & 5 & \\
\hline
\end{tabular}

Quando a informação solicitada foi sobre a faixa de remuneração mensal atual, 45,4\% declararam se situar acima de $\mathrm{R} \$ 5.000,00$ até $\mathrm{R} \$ 10.000,00$. Apenas 6,9\% informaram receber até $\mathrm{R} \$ 5.000,00$ e $36,9 \%$ acima de $\mathrm{R} \$ 15.000,00$. Dos que estão na faixa mais alta de remuneração, cerca de $45,0 \%$ deles se titularam mais recentemente (2000-2005) e pouco mais de 4,0\% são mulheres. A maioria absoluta dos doutores que mantêm sua principal atividade remunerada ligada ao mercado $(75,0 \%)$ declarou perceber acima de $\mathrm{R} \$ 15.000,00$ como remuneração mensal e nenhum deles até $\mathrm{R} \$$ 5.000,00; os doutores que mantêm sua principal atividade remunerada ligada à academia, em sua maioria $(60,0 \%)$, estão situados entre a faixa de remuneração que vai de $\mathrm{R} \$ 5.000,00$ até $\mathrm{R} \$ 10.000,00$; apenas 20,0\% recebendo acima de $\mathrm{R} \$ 15.000,00$ (Tabela 6). 
Tabela 6

Remuneração no Ingresso e Atual dos Doutores em Ciências Contábeis

\begin{tabular}{|c|c|c|c|c|c|c|}
\hline & N & 0 & & mia & & \\
\hline & 19 & 10 & $\mathbf{N}_{1}$ & $\%$ & $\mathbf{N}_{2}$ & $\%$ \\
\hline Remuneração no Ingresso & & & & & & \\
\hline $\mathrm{N}$ & & & & & & \\
\hline Missing & & & & & & \\
\hline Até $\mathrm{R} \$ 5.000,00$ & 53 & 41,5 & 38 & 60,3 & 15 & 23,1 \\
\hline Acima de $\mathrm{R} \$ 5.000,00$ até $\mathrm{R} \$ 10.000,00$ & 47 & 36,7 & 18 & 28,6 & 29 & 44,6 \\
\hline Acima de $\mathrm{R} \$ 10.000,00$ até $\mathrm{R} \$ 15.000,00$ & 14 & 10,9 & 4 & 6,3 & 10 & 15,4 \\
\hline Acima de $\mathrm{R} \$ 15.000,00$ & 14 & 10,9 & 3 & 4,8 & 11 & 16,9 \\
\hline Total & 128 & 100 & 63 & 100 & 65 & 100 \\
\hline Remuneração Atual & & & & & & \\
\hline $\mathrm{N}$ & & & & & & \\
\hline Missing & & & & & & \\
\hline Até R\$ 5.000,00 & 9 & 6,9 & 9 & 10,0 & & \\
\hline Acima de $\mathrm{R} \$ 5.000,00$ até $\mathrm{R} \$ 10.000,00$ & 59 & 45,4 & 54 & 60,0 & 5 & 12,5 \\
\hline Acima de $\mathrm{R} \$ 10.000,00$ até $\mathrm{R} \$ 15.000,00$ & 14 & 10,8 & 9 & 10,0 & 5 & 12,5 \\
\hline Acima de $\mathrm{R} \$ 15.000,00$ & 48 & 36,9 & 18 & 20,0 & 30 & 75,0 \\
\hline Total & 130 & 100 & 90 & 100 & 40 & 100 \\
\hline
\end{tabular}

Dos $20,0 \%$ dos doutores que desenvolvem sua principal atividade remunerada nas academias que declararam remuneração acima de R $\$ 15.000,00$, mais de 70,0\% estão em IES privadas, quase 65,0\% vinculados a uma universidade e mais de $94,0 \%$ desenvolvendo pesquisas. Apenas na faixa de remuneração que se situa acima de $\mathrm{R} \$ 10.000,00$ até $\mathrm{R} \$ 15.000,00$ não se pode rejeitar a hipótese de que a remuneração paga pelo mercado é igual àquela paga pela academia $\left(Z_{c a l}-0,42>-2\right)$, em nível de significância de 4,5\%. O teste de significância para igualdade entre duas proporções populacionais, realizado para todas as outras faixas de remuneração, mostrou que a remuneração do mercado é diferente da academia. Quando se realiza o teste de significância para igualdade entre 2 médias $(t$ de Student), rejeita-se a hipótese da igualdade entre a remuneração média (R\$ 9.750,00 com desvio padrão de R\$ 4.576,59) recebida pelos doutores em Ciências Contábeis que mantêm sua principal atividade remunerada vinculada à academia e a remuneração média (R\$ 16.000,00 com desvio padrão de $\mathrm{R}$ \$ 3.729, 65) recebida pelos doutores em Ciências Contábeis que mantêm sua principal atividade remunerada vinculada ao mercado, com um nível de significância de 5,\% $\left(t_{c a l}-7,59<-1,96\right)$.

Quando questionados sobre sua faixa de remuneração, na época de ingresso no curso, 41,4\% declararam perceber rendimentos que não ultrapassavam a R \$ 5.000,00 (mais de 70\% deles com principal atividade remunerada vinculada à academia) e apenas 10,9\% acima de R\$15.000,00 (quase $80 \%$ desenvolviam a principal atividade remunerada no mercado). A situação é praticamente inversa à atual; demonstra a influência positiva do curso na remuneração, mesmo não tendo sido esta uma percepção nos doutores, visto que a remuneração ocupou apenas a décima sexta posição na classificação de intensidade dos fatores que se alteram com o doutorado, conforme poderá ser constatado no item Influências do Doutorado em Ciências Contábeis. Na Tabela 6, apresenta-se um comparativo das remunerações na época do ingresso no curso e do preenchimento do questionário. 
Pela análise da Tabela 6, percebe-se que, no grupo, houve uma migração daqueles que percebiam remuneração na faixa de até $\mathrm{R} \$ 5.000,00$ para as outras faixas de renda, principalmente para aquela situada acima de $\mathrm{R} \$ 15.000,00$. O teste de significância para igualdade entre duas proporções populacionais permite rejeitar a hipótese, em nível de significância de 4,5\%, de que o percentual dos que ganhavam até $\mathrm{R} \$ 5.000$, 00 no ingresso ao doutorado é igual aos que percebem essa remuneração hoje $\left(Z_{c a l} 5,69>2\right)$. A faixa de remuneração acima de $\mathrm{R} \$ 10.000,00$ até $\mathrm{R} \$ 15.000,00$ não sofreu alteração $\left(Z_{c a l} 0,02<2\right)$.

Quando o foco passa a ser aqueles que declararam manter sua principal atividade remunerada vinculada à academia, percebe-se que o percentual de respondentes que declarou perceber rendimentos de até $\mathrm{R}$ \$ 5.000,00 no ingresso ao curso reduziu-se de 60,3\% para 10,0\% após a conclusão. Diferença significativa a um nível de significância de 4,5\% $\left(Z_{c a l} 6,63>2\right)$. Aqueles que haviam registrado receber acima de $\mathrm{R} \$ 15.000,00$ antes da realização do curso, 4,8\% dos respondentes, passaram, após o término, a representar $20,0 \%$ dos doutores $\left(Z_{c a l}-2,69<-2\right)$, evidenciando-se, com nível de significância de 4,5\%, que o percentual dos que percebiam remuneração acima de R $\$ 15.000,00$ no ingresso ao curso e o percentual dos que recebem hoje possuem diferenças significativas. Pelo teste de significância para igualdade entre 2 médias ( $t$ de Student) é possível rejeitar a hipótese de que a média da remuneração recebida pelo conjunto de doutores em Ciências Contábeis que mantinha sua principal atividade remunerada vinculada à academia, na época de ingresso ao curso (R\$ 6.206,35 com desvio padrão de R \$ 3.571,43), seja igual à média da remuneração recebida pelo conjunto de doutores em Ciências Contábeis que, atualmente, mantêm sua principal atividade remunerada vinculada à academia (R \$ 9.750,00 com desvio padrão de R \$ 4.576,59), com um grau de significância de $5 \%\left(t_{c a l}-5,14<-\right.$ 1,96). Nos doutores vinculados ao mercado, as maiores alterações ocorreram na faixa que percebia até R \$ 5.000,00. Representava 23,1\% dos ingressantes e não aparece dentre os que se acham vinculados ao mercado após a titulação. Além disso, $75 \%$ dos doutores que atuam no mercado, como forma principal de rendimento, ganham acima de $\mathrm{R} \$ 15.000,00$, enquanto no ingresso ao curso não representavam 17,0\% $\left(Z_{c a l}-5,93<-2\right)$. O teste de significância para igualdade entre 2 médias $(t$ de Student) confirma as diferenças apontadas, rejeitando a hipótese de que a remuneração média recebida pelo conjunto de doutores em Ciências Contábeis que mantinha sua principal atividade remunerada vinculada ao mercado no ingresso ao curso ( $\mathrm{R} \$ 9.238,46$ com desvio padrão de $\mathrm{R} \$ 4.759,95$ ) seja igual à remuneração média recebida hoje pelo conjunto de doutores em Ciências Contábeis com principal atividade remunerada vinculada ao mercado ( $\mathrm{R} \$ 16.000,00$ com desvio padrão de $\mathrm{R} \$$ 3.729,65), com um nível de significância de 5\% $\left(t_{c a l}-7,65<-1,98\right)$ (Tabela 6).

\section{Doutorado em Ciências Contábeis, Motivações e Contribuições}

Os fatores que os motivaram para a realização do doutorado foi um dos questionamentos. Solicitouse que avaliassem dez quesitos, conforme uma escala que varia de 0 para não pesou; 1 pesou um pouco; 2 peso médio; e 3 pesou muito.

A análise das motivações para cursar o doutorado pode ser feita a partir das informações contidas na Tabela 7. Entre elas, destaca-se o fato de que o doutorado é visto principalmente como base de ascensão ou ingresso na carreira docente. Mais de $80 \%$ dos entrevistados consideraram que esse fator pesou muito na sua motivação para realizar o doutorado. 
Tabela 7

Fatores que Pesaram na Decisão de Fazer o Doutorado em Ciências Contábeis

\begin{tabular}{|c|c|c|c|c|c|c|c|c|}
\hline \multirow{2}{*}{ Fatores } & & & \multirow{2}{*}{$\mathbf{N}$} & \multirow{2}{*}{$\%$} & \multicolumn{2}{|c|}{ Academia } & \multicolumn{2}{|c|}{ Mercado } \\
\hline & & & & & $\mathbf{N}_{1}$ & $\%$ & $\mathbf{N}_{2}$ & $\%$ \\
\hline \multicolumn{2}{|c|}{ Corrigir deficiências do mestrado } & 0 - Não pesou & 82 & 63,6 & 54 & 60,0 & 28 & 71,9 \\
\hline $\mathrm{N}$ & 129 & 1 - Pesou um pouco & 28 & 21,7 & 21 & 23,3 & 7 & 17,9 \\
\hline \multirow[t]{2}{*}{ Missing } & 3 & 2 - Peso médio & 12 & 9,3 & 10 & 11,1 & 2 & 5,1 \\
\hline & & 3 - Pesou muito & 7 & 5,4 & 5 & 5,6 & 2 & 5,1 \\
\hline \multicolumn{2}{|c|}{ Seguir/aprimorar carreira profissional } & 0 - Não pesou & 11 & 8,5 & 8 & 8,9 & 3 & 7,3 \\
\hline $\mathrm{N}$ & 130 & 1 - Pesou um pouco & 16 & 12,3 & 11 & 12,4 & 5 & 12,2 \\
\hline \multirow[t]{2}{*}{ Missing } & 2 & 2 - Peso médio & 35 & 26,9 & 25 & 28,1 & 10 & 24,4 \\
\hline & & 3 - Pesou muito & 68 & 52,3 & 45 & 50,6 & 23 & 56,1 \\
\hline \multicolumn{2}{|c|}{ Seguir/aprimorar carreira docente } & 0 - Não pesou & & & & & & \\
\hline $\mathrm{N}$ & 132 & 1 - Pesou um pouco & 9 & 6,8 & 4 & 4,4 & 5 & 12,2 \\
\hline \multirow[t]{2}{*}{ Missing } & 0 & 2 - Peso médio & 13 & 9,9 & 5 & 5,5 & 8 & 19,5 \\
\hline & & 3 - Pesou muito & 110 & 83,3 & 82 & 90,1 & 28 & 68,3 \\
\hline \multicolumn{2}{|c|}{ Seguir/aprimorar carreira pesquisador } & 0 - Não pesou & 3 & 2,3 & 1 & 1,1 & 2 & 4,9 \\
\hline $\mathrm{N}$ & 132 & 1 - Pesou um pouco & 12 & 9,1 & 7 & 7,7 & 5 & 12,2 \\
\hline \multirow[t]{2}{*}{ Missing } & 0 & 2 - Peso médio & 20 & 15,1 & 8 & 8,8 & 12 & 29,3 \\
\hline & & 3 - Pesou muito & 97 & 73,5 & 75 & 82,4 & 22 & 53,7 \\
\hline \multicolumn{2}{|c|}{ Ampliar oportunidades de trabalho } & 0 - Não pesou & 11 & 8,3 & 4 & 4,4 & 7 & 17,1 \\
\hline $\mathrm{N}$ & 132 & 1 - Pesou um pouco & 16 & 12,2 & 9 & 9,9 & 7 & 17,1 \\
\hline \multirow[t]{2}{*}{ Missing } & 0 & 2 - Peso médio & 35 & 26,5 & 25 & 27,5 & 10 & 24,4 \\
\hline & & 3 - Pesou muito & 70 & 53,0 & 53 & 58,2 & 17 & 41,4 \\
\hline \multicolumn{2}{|l|}{ Obter mais conhecimentos } & 0 - Não pesou & & & & & & \\
\hline $\mathrm{N}$ & 132 & 1 - Pesou um pouco & 4 & 3,0 & 1 & 1,1 & 3 & 7,3 \\
\hline \multirow[t]{2}{*}{ Missing } & 0 & 2 - Peso médio & 21 & 15,9 & 14 & 15,4 & 7 & 17,1 \\
\hline & & 3 - Pesou muito & 107 & 81,1 & 76 & 83,5 & 31 & 75,6 \\
\hline \multicolumn{2}{|l|}{ Obter melhor nível de renda } & 0 - Não pesou & 16 & 12,1 & 6 & 6,6 & 10 & 24,4 \\
\hline $\mathrm{N}$ & 132 & 1 - Pesou um pouco & 19 & 14,4 & 9 & 9,9 & 10 & 24,4 \\
\hline \multirow[t]{2}{*}{ Missing } & 0 & 2 - Peso médio & 33 & 25,0 & 26 & 28,6 & 7 & 17,1 \\
\hline & & 3 - Pesou muito & 64 & 48,5 & 50 & 54,9 & 14 & 34,1 \\
\hline \multicolumn{2}{|l|}{ Obter diferenciação profissional } & 0 - Não pesou & 4 & 3,0 & 2 & 2,2 & 2 & 4,9 \\
\hline $\mathrm{N}$ & 132 & 1 - Pesou um pouco & 12 & 9,1 & 5 & 5,5 & 7 & 17,1 \\
\hline \multirow[t]{2}{*}{ Missing } & 0 & 2 - Peso médio & 30 & 22,7 & 21 & 23,1 & 9 & 22,0 \\
\hline & & 3 - Pesou muito & 86 & 65,2 & 63 & 69,2 & 23 & 56,0 \\
\hline
\end{tabular}


Tabela 7 (continuação)

\begin{tabular}{|c|c|c|c|c|c|c|c|c|}
\hline \multirow{2}{*}{\multicolumn{2}{|c|}{ Fatores }} & & \multirow{2}{*}{$\mathbf{N}$} & \multirow{2}{*}{$\%$} & \multicolumn{2}{|c|}{ Academia } & \multicolumn{2}{|c|}{ Mercado } \\
\hline & & & & & $\mathbf{N}_{1}$ & $\%$ & $\mathbf{N}_{2}$ & $\%$ \\
\hline \multicolumn{2}{|c|}{ Melhorar a competitividade profissional } & 0 - Não pesou & 8 & 6,1 & 4 & 4,4 & 4 & 9,8 \\
\hline $\mathrm{N}$ & 132 & 1 - Pesou um pouco & 17 & 12,9 & 11 & 12,1 & 6 & 14,6 \\
\hline \multirow[t]{2}{*}{ Missing } & 0 & 2 - Peso médio & 41 & 31,0 & 31 & 34,1 & 10 & 24,4 \\
\hline & & 3 - Pesou muito & 66 & 50,0 & 45 & 49,5 & 21 & 51,2 \\
\hline Alcançar prestígio profissional & & 0 - Não pesou & 12 & 9,1 & 7 & 7,7 & 5 & 12,0 \\
\hline $\mathrm{N}$ & 132 & 1 - Pesou um pouco & 26 & 19,7 & 17 & 18,7 & 9 & 22,0 \\
\hline \multirow[t]{2}{*}{ Missing } & 0 & 2 - Peso médio & 29 & 22,0 & 20 & 22,0 & 9 & 22,0 \\
\hline & & 3 - Pesou muito & 65 & 49,2 & 47 & 51,6 & 18 & 44,0 \\
\hline Outro & & 0 - Não pesou & & & & & & \\
\hline $\mathrm{N}$ & 23 & 1 - Pesou um pouco & & & & & & \\
\hline \multirow[t]{2}{*}{ Missing } & 109 & 2 - Peso médio & 5 & 21,7 & 5 & 22,7 & & \\
\hline & & 3 - Pesou muito & 18 & 78,3 & 17 & 77,3 & 1 & 100,0 \\
\hline
\end{tabular}

Esse percentual passa dos 90\%, quando a análise é centrada nos doutores que desenvolvem sua principal atividade remunerada na academia. Essa mesma forte motivação foi encontrada por Matos et al. (2002), quando investigaram os doutores em Administração; Oliveira e Weber (2002), os doutores em Agronomia; Braga e Azevedo (2002), os doutores em Bioquímica; e Oliven e Neves (2002), os doutores em Clínica Médica. Stirati e Cesaratto (1995) também constataram, como principal motivação para a busca pelo doutoramento na Itália, o foco na carreira universitária e Mangematin (2000) obteve o mesmo com seu estudo com 399 titulados com um Ph.D. em Ciências de Engenharia, egressos da Universidade de Grenoble, na França, de 1984 a 1996.

Corrigir as deficiências do mestrado não foi motivo para ingressar no doutorado para mais de $60 \%$ dos respondentes. Apenas 5,4\% deles atribuíram um peso alto a esse fator. Exceto essa motivação, observa-se que todas as outras tiveram um comportamento de respostas relativamente igual, representando um peso de médio a alto na decisão de realizar o doutoramento. Cerca de $17 \%$ dos entrevistados alegaram outras motivações para a realização do doutorado, que significaram um peso de médio a alto. Dentre elas, a mais citada está ligada à realização e satisfação pessoal (Tabela 7).

Foi solicitado aos entrevistados que avaliassem as contribuições que o curso trouxe para as atividades atualmente desenvolvidas. Apresentaram-se aos investigados quatro alternativas para serem avaliadas, conforme a contribuição que estariam fornecendo para seu exercício profissional: formação teórica, experiência em pesquisa, atualização dos conhecimentos e contatos acadêmicos ou profissionais. Os dados produzidos pela investigação tendem a indicar uma avaliação altamente positiva, quanto às contribuições do curso para o desenvolvimento de suas atividades atuais (Tabela 8). 
Tabela 8

Contribuições do Doutorado em Ciências Contábeis para as Atividades Atuais

\begin{tabular}{|c|c|c|c|c|c|c|c|c|}
\hline \multirow{2}{*}{\multicolumn{2}{|c|}{ Contribuições }} & & \multirow{2}{*}{$\mathbf{N}$} & \multirow{2}{*}{$\%$} & \multicolumn{2}{|c|}{ Academia } & \multicolumn{2}{|c|}{ Mercado } \\
\hline & & & & & $\mathbf{N}_{1}$ & $\%$ & $\mathbf{N}_{2}$ & $\%$ \\
\hline $\begin{array}{l}\text { A formação teórica (básica ou } \\
\text { aplicada) do doutorado }\end{array}$ & & 0 - Não tem contribuído & & - & & - & & - \\
\hline $\mathrm{N}$ & 131 & 1 - Baixa contribuição & 5 & 3,8 & 3 & 3,3 & 2 & 4,9 \\
\hline \multirow[t]{2}{*}{ Missing } & 1 & 2 - Média contribuição & 37 & 28,2 & 23 & 25,6 & 14 & 34,1 \\
\hline & & 3 - Alta contribuição & 89 & 68 & 64 & 71,1 & 25 & 60,9 \\
\hline $\begin{array}{l}\text { A experiência em pesquisa no } \\
\text { doutorado }\end{array}$ & & 0 - Não tem contribuído & & & & & & \\
\hline N & 131 & 1 - Baixa contribuição & 10 & 7,6 & 6 & 6,7 & 4 & 9,8 \\
\hline \multirow[t]{2}{*}{ Missing } & 1 & 2 - Média contribuição & 54 & 41,2 & 32 & 35,6 & 22 & 53,7 \\
\hline & & 3 - Alta contribuição & 67 & 51,2 & 52 & 57,7 & 15 & 36,5 \\
\hline $\begin{array}{l}\text { A atualização dos conhecimento } \\
\text { em minha área de doutorado }\end{array}$ & & 0 - Não tem contribuído & 1 & 0,8 & & & 1 & 2,5 \\
\hline $\mathrm{N}$ & 131 & 1 - Baixa contribuição & 8 & 6,1 & 4 & 4,4 & 4 & 9,8 \\
\hline \multirow[t]{2}{*}{ Missing } & 1 & 2 - Média contribuição & 49 & 37,4 & 34 & 37,9 & 15 & 36,5 \\
\hline & & 3 - Alta contribuição & 73 & 55,7 & 52 & 57,7 & 21 & 51,2 \\
\hline $\begin{array}{l}\text { Os contatos acadêmicos ou } \\
\text { profissionais que obtive durante } \\
\text { doutorado }\end{array}$ & e & 0 - Não tem contribuído & 7 & 5,3 & 2 & 2,2 & 5 & 12,2 \\
\hline $\mathrm{N}$ & 131 & 1 - Baixa contribuição & 23 & 17,6 & 12 & 13,3 & 11 & 26,8 \\
\hline \multirow[t]{2}{*}{ Missing } & 1 & 2 - Média contribuição & 46 & 35,1 & 33 & 36,7 & 13 & 31,7 \\
\hline & & 3 - Alta contribuição & 55 & 42 & 43 & 47,8 & 12 & 29,3 \\
\hline Outro & & 0 - Não tem contribuído & & & & & & - \\
\hline $\mathrm{N}$ & 13 & 1 - Baixa contribuição & & & & & & - \\
\hline \multirow[t]{2}{*}{ Missing } & 119 & 2 - Média contribuição & 1 & 7,7 & 1 & 10,0 & & - \\
\hline & & 3 - Alta contribuição & 12 & 92,3 & 9 & 90,0 & 3 & 100 \\
\hline
\end{tabular}

Quando indagados sobre a contribuição da formação teórica para suas atuais atividades profissionais, 68,0\% dos respondentes avaliaram essa contribuição como alta, principalmente para aqueles que têm sua principal atividade remunerada ligada à academia (71,1\%). Esse resultado foi o mesmo que o encontrado por Matos et al. (2002) nos doutores em Administração; Oliveira e Weber (2002), com os de Agronomia; Sampaio e Velloso (2002), na Engenharia Civil; e Braga e Azevedo (2002), com os doutores em Química, que também consideraram essa contribuição como a mais significativa.

O contato com as atividades de pesquisas se apresentou como contribuição alta para mais da metade dos pesquisados. No entanto, para a maioria daqueles que estão vinculados ao mercado, essa contribuição foi considerada apenas mediana. Também a atualização dos conhecimentos foi avaliada positivamente pela maior parte dos entrevistados (55,7\%). Deve-se registrar que os contatos acadêmicos e profissionais, mantidos durante o curso, foram avaliados pela maioria dos entrevistados 
como média (35,1\%) e alta (42,0\%). Os profissionais que mantêm sua principal atividade remunerada vinculada ao mercado consideraram a contribuição dos contatos mantidos, uniformemente distribuída, entre baixa (26,8\%), média (31,7\%) e alta (29,3\%); $12,2 \%$ deles consideraram que esses contatos não contribuíram em nada para suas atividades profissionais atuais.

Pode-se observar que a ligação da principal atividade ao mercado ou à academia produz variação na avaliação dos respondentes. Há certa concordância na avaliação de dois dos itens propostos (formação teórica e atualização dos conhecimentos) como sendo de alta contribuição para o trabalho atual. Com relação à experiência em pesquisa e aos contatos, apresenta-se certa diferenciação entre a distribuição do nível da contribuição. Quase 10\% dos entrevistados salientaram outras contribuições do doutorado para suas atividades atuais, dentre elas: "a mudança de postura produzida pela vivência em um ambiente aberto ao questionamento e à inovação" e "desenvolvimento do pensamento crítico".

\section{Influências do Doutorado em Ciências Contábeis}

Indagou-se aos pesquisados se a formação no doutorado trouxe mudanças em aspectos relevantes da vida dos egressos, positivas ou negativas. Procurou-se avaliar em que grau de intensidade elas ocorreram. Para isso solicitou-se aos entrevistados que conferissem nota de 0 a 10, a 19 fatores da teoria do capital humano estabelecidos por Cunha (2007) em duas aplicações da técnica Delphi, como sujeitos a alterações com um título de doutoramento.

A expectativa de que o curso altera positivamente aspectos do desenvolvimento profissional e social dos egressos se confirmou. A pontuação alcançada pelos fatores, bem como suas estatísticas constam da Tabela 9, em ordem dos escores alcançados. Os fatores mais bem avaliados, de acordo com o grau de intensidade percebida, foram, respectivamente: respeitabilidade e reconhecimento acadêmico/profissional (1111 pontos, representando 84,2\% da pontuação possível total); diferenciação profissional (1095 pontos, ou 83,0\%); espírito acadêmico (1085 pontos, ou 82,2\%); amadurecimento pessoal (1073 pontos, ou 81,3\%); produção acadêmica (1071 pontos e 81,1\%); e oportunidades na carreira (1042 pontos e 79,0\%).

Tabela 9

Fatores que são Influenciados pelo Título de Doutor em Ciências Contábeis

\begin{tabular}{|c|c|c|c|c|c|c|c|c|c|c|c|c|}
\hline & \multicolumn{2}{|c|}{ Escore } & \multirow[b]{2}{*}{ Média } & \multirow[b]{2}{*}{ Mediana } & \multirow[b]{2}{*}{ Moda } & \multirow[b]{2}{*}{$\begin{array}{l}\text { Desvio } \\
\text { Padrão }\end{array}$} & \multirow[b]{2}{*}{ Mínimo } & \multirow[b]{2}{*}{ Máximo } & \multirow[b]{2}{*}{$\begin{array}{c}\text { CV- } \\
\%\end{array}$} & \multicolumn{3}{|c|}{ Quartis } \\
\hline & $\mathbf{N}$ & $\begin{array}{c}\% \\
(1320=100)\end{array}$ & & & & & & & & 25 & 50 & 75 \\
\hline $\begin{array}{l}\text { Respeitabilidade e } \\
\text { reconhecimento } \\
\text { acadêmico/profissional }\end{array}$ & 1111 & 84,2 & 8,6 & 9 & 10 & 1,9 & 0 & 10 & 22,5 & 8 & 9 & 10 \\
\hline Diferenciação profissional & 1095 & 83,0 & 8,4 & 9 & 10 & 2,0 & 0 & 10 & 24,3 & 8 & 9 & 10 \\
\hline Espírito acadêmico & 1085 & 82,2 & 8,4 & 9 & 10 & 2,0 & 0 & 10 & 26,5 & 8 & 9 & 10 \\
\hline Amadurecimento pessoal & 1073 & 81,3 & 8,3 & 9 & 10 & 2,1 & 0 & 10 & 25,9 & 8 & 9 & 10 \\
\hline Produção acadêmica & 1071 & 81,1 & 8,3 & 9 & 10 & 1,8 & 2 & 10 & 21,9 & 7 & 9 & 10 \\
\hline Oportunidades na carreira & 1042 & 79,0 & 8,0 & 8 & 10 & 2,3 & 0 & 10 & 28,6 & 7 & 8 & 10 \\
\hline Autonomia profissional & 1041 & 78,9 & 8,0 & 9 & 10 & 2,4 & 0 & 10 & 29,8 & 7 & 9 & 10 \\
\hline Habilidade cognitiva & 1015 & 76,9 & 7,8 & 8 & 8 & 2,1 & 0 & 10 & 26,2 & 7 & 8 & 9 \\
\hline Competências analíticas & 1013 & 76,7 & 7,9 & 8 & 10 & 2,3 & 0 & 10 & 29,8 & 7 & 8 & 9,5 \\
\hline Empregabilidade & 1013 & 76,7 & 7,7 & 8 & 10 & 2,5 & 0 & 10 & 32,2 & 6 & 8 & 10 \\
\hline Prestígio & 1008 & 76,4 & 7,7 & 8 & 10 & 2,4 & 0 & 10 & 31,5 & 7 & 8 & 10 \\
\hline
\end{tabular}

Continua 


\section{Tabela 9 (continuação)}

\begin{tabular}{|c|c|c|c|c|c|c|c|c|c|c|c|c|}
\hline & \multicolumn{2}{|r|}{ Escore } & \multirow[b]{2}{*}{ Média } & \multirow[b]{2}{*}{ Mediana } & \multirow[b]{2}{*}{ Moda } & \multirow[b]{2}{*}{$\begin{array}{l}\text { Desvio } \\
\text { Padrão }\end{array}$} & \multirow[b]{2}{*}{ Mínimo } & \multirow[b]{2}{*}{ Máximo } & \multirow[b]{2}{*}{$\begin{array}{c}\text { CV- } \\
\%\end{array}$} & \multicolumn{3}{|c|}{ Quartis } \\
\hline & $\mathbf{N}$ & $\begin{array}{c}\% \\
(1320=100)\end{array}$ & & & & & & & & 25 & 50 & 75 \\
\hline Produtividade & 996 & 75,5 & 7,6 & 8 & 8 & 2,3 & 0 & 10 & 30,1 & 6 & 8 & 9 \\
\hline Mobilidade profissional & 972 & 73,6 & 7,5 & 8 & 10 & 2,6 & 0 & 10 & 34,3 & 7 & 8 & 10 \\
\hline Responsabilidade social & 941 & 71,3 & 7,2 & 8 & 8 & 2,6 & 0 & 10 & 36,2 & 6 & 8 & 9 \\
\hline Status & 936 & 70,9 & 7,2 & 8 & 10 & 2,8 & 0 & 10 & 38,2 & 5 & 8 & 9 \\
\hline Remuneração & 932 & 70,6 & 7,1 & 8 & 8 & 2,5 & 0 & 10 & 35,0 & 6 & 8 & 9 \\
\hline Promoção social & 908 & 68,8 & 6,9 & 8 & 8 & 2,8 & 0 & 10 & 40,8 & 5 & 8 & 9 \\
\hline Estabilidade profissional & 897 & 68,0 & 6,9 & 8 & 8 & 3,0 & 0 & 10 & 43,3 & 5 & 8 & 9 \\
\hline Estilos de vida & 830 & 62,9 & 6,3 & 7 & 8 & 3,1 & 0 & 10 & 48,6 & 5 & 7 & 9 \\
\hline
\end{tabular}

De forma geral, os 19 fatores foram bem avaliados pelos entrevistados, indicando um panorama de impacto bastante positivo do título na vida dos egressos. O fator que alcançou a menor pontuação, estilo de vida, obteve quase $2 / 3$ da pontuação possível, com média de pontos de 6,34 . O conjunto das percepções revela, assim, que a titulação obtida tem sido positiva para o desenvolvimento dos egressos. Os entrevistados também identificaram outros fatores que se alteraram com a titulação obtida por eles, entre os quais o empreendedorismo e a satisfação por alcançar objetivo pessoal. A observação de um dos respondentes indica o grau de alterações proporcionadas pelo título: "Ser doutorando já antecipou quase todos os fatores acima. A condição de doutor apenas consolidou. Acredito que seja por causa da escassez de doutores em contábeis”.

Quando se analisam os escores alcançados pelos fatores, considerando a principal atividade remunerada informada pelo entrevistado, percebe-se que o grupo dos acadêmicos possui percepções diferenciadas, quando comparado ao grupo que possui a principal atividade remunerada vinculada ao mercado, em termos de intensidade dos fatores. Apenas um fator tem a mesma classificação entre os acadêmicos e os de mercado. O primeiro lugar, entre o grupo dos acadêmicos, é respeitabilidade e reconhecimento acadêmico/profissional (escore de 807, representando 88,7\% dos 910 pontos possíveis - 10 X 91 respondentes com principal atividade remunerada vinculada à academia), enquanto, no grupo daqueles que possuem a principal atividade remunerada vinculada ao mercado, o primeiro lugar é ocupado pelo fator espírito acadêmico (escore de 328, representando 80,0\% dos 410 pontos possíveis).

Observa-se que o escore alcançado pelos fatores, quando analisados os resultados vinculados à academia, se apresenta maior, percentualmente, do que o escore alcançado com principal atividade remunerada vinculada ao mercado. Como exemplo, o fator remuneração, que ocupa a $14^{\mathrm{a}}$. posição no grupo de acadêmicos, alcançou $74,7 \%$ de toda a pontuação possível, enquanto o fator status, que atingiu a mesma colocação ( $14^{\circ}$. lugar) no grupo com principal atividade remunerada vinculada ao mercado, alcançou apenas 65,6\% dos pontos possíveis. O fator produção acadêmica, que é o segundo colocado para os acadêmicos, obteve $86,3 \%$ dos pontos, enquanto o fator que ocupa a mesma classificação para os de mercado atingiu 76,8\%.

A evidência que se apresenta é que as percepções dos doutores em Ciências Contábeis, que possuem sua principal atividade remunerada vinculada à academia, são mais positivas quanto às influências do título nos seus desenvolvimentos do que as percepções dos que possuem a principal atividade remunerada vinculada ao mercado. Na Tabela 10, pode-se observar a colocação dos fatores dentro do conjunto daqueles que possuem a principal atividade remunerada vinculada à academia e daqueles que a possuem vinculada ao mercado. 
Tabela 10

Fatores que são Influenciados pelo Título de Doutor em Ciências Contábeis Segregados por Principal Atividade Remunerada

\begin{tabular}{|c|c|c|c|c|c|c|}
\hline & \multicolumn{4}{|c|}{ Escore } & \multicolumn{2}{|c|}{ Classificação } \\
\hline & \multicolumn{2}{|c|}{ Academia } & \multicolumn{2}{|c|}{ Mercado } & \multirow[b]{2}{*}{ Academia } & \multirow[b]{2}{*}{ Mercado } \\
\hline & $\mathbf{N}_{1}$ & $\begin{array}{c}\% \\
(910=100)\end{array}$ & $\mathbf{N}_{2}$ & $\begin{array}{c}\% \\
(410=100)\end{array}$ & & \\
\hline $\begin{array}{l}\text { Respeitabilidade e reconhecimento } \\
\text { acadêmico/profissional }\end{array}$ & 807 & 88,7 & 304 & 74,1 & $1^{\mathrm{o}}$ & $4^{\circ}$ \\
\hline Produção acadêmica & 785 & 86,3 & 286 & 69,8 & $2^{\circ}$ & $9^{\circ}$ \\
\hline Amadurecimento pessoal & 783 & 86,0 & 290 & 70,7 & $3^{\circ}$ & $8^{\circ}$ \\
\hline Diferenciação profissional & 780 & 85,7 & 315 & 76,8 & $4^{\circ}$ & $2^{\circ}$ \\
\hline Oportunidades na carreira & 766 & 84,2 & 276 & 67,3 & $5^{\circ}$ & $12^{\circ}$ \\
\hline Espírito acadêmico & 757 & 83,2 & 328 & 80,0 & $6^{\circ}$ & $1^{\circ}$ \\
\hline Autonomia profissional & 747 & 82,1 & 294 & 71,7 & $7^{\circ}$ & $6^{\circ}$ \\
\hline Empregabilidade & 741 & 81,4 & 272 & 66,3 & $8^{\circ}$ & $13^{\circ}$ \\
\hline Mobilidade profissional & 730 & 80,2 & 242 & 59,0 & $9^{\circ}$ & $17^{\circ}$ \\
\hline Prestígio & 722 & 79,3 & 286 & 69,8 & $10^{\circ}$ & $9^{\circ}$ \\
\hline Habilidade cognitiva & 714 & 78,5 & 301 & 73,4 & $11^{\circ}$ & $5^{\circ}$ \\
\hline Produtividade & 705 & 77,5 & 291 & 71,0 & $12^{\circ}$ & $7^{\circ}$ \\
\hline Competências analíticas & 699 & 76,8 & 314 & 76,6 & $13^{\circ}$ & $3^{\circ}$ \\
\hline Remuneração & 680 & 74,7 & 252 & 61,5 & $14^{\circ}$ & $16^{\circ}$ \\
\hline Estabilidade profissional & 672 & 73,8 & 225 & 54,9 & $15^{\circ}$ & $18^{\circ}$ \\
\hline Status & 667 & 73,3 & 269 & 65,6 & $16^{\circ}$ & $14^{\circ}$ \\
\hline Responsabilidade social & 661 & 72,6 & 280 & 68,3 & $17^{\circ}$ & $11^{\circ}$ \\
\hline Promoção social & 649 & 71,3 & 259 & 63,2 & $18^{\circ}$ & $15^{\circ}$ \\
\hline Estilos de vida & 635 & 69,8 & 195 & 47,6 & $19^{\circ}$ & $19^{\circ}$ \\
\hline
\end{tabular}

Mesmo com as diferenciações observadas, estas não se sustentam estatisticamente. Encontrou-se um coeficiente de correlação por postos de Spearman (rs) de 0,58 (p-value 0,01), concluindo-se, em nível de significância de $1 \%$, que há correlação entre as classificações dos fatores que são influenciados pelo doutoramento em Ciências Contábeis realizadas pelos doutores com principal atividade remunerada vinculada à academia e pelos doutores com principal atividade remunerada vinculada ao mercado.

\section{CONCLUSÕES}

Os pressupostos da teoria do capital humano estabelecem que as pessoas se educam e que o principal efeito da educação é a mudança que ela provoca nas habilidades e conhecimentos de quem estuda. Quanto maior o nível de escolaridade alcançado, maior o desenvolvimento das habilidades cognitivas e de produtividade. A consequência prevista do aumento de habilidades e de produtividade é a melhora no nível de renda, na qualidade de vida, nas oportunidades profissionais e sociais e na responsabilidade social. 
Tendo por base esse arcabouço teórico, o propósito principal desta pesquisa foi identificar e analisar as avaliações e percepções dos doutores em Ciências Contábeis, titulados pela FEA/USP, sobre as influências do doutorado nos seus desenvolvimentos e nas suas responsabilidades sociais. Os achados da pesquisa confirmaram as expectativas, explicações e previsões da teoria. Na percepção dos egressos, os 19 fatores, possíveis de serem alterados, que lhes foram apresentados, identificados na teoria do capital humano e levantados em duas aplicações da técnica Delphi, foram substancialmente influenciados com a titulação. Foram eles: respeitabilidade e reconhecimento acadêmico/profissional, diferenciação profissional, espírito acadêmico, amadurecimento pessoal, produção acadêmica, oportunidades na carreira, autonomia profissional, habilidades cognitivas, competências analíticas, empregabilidade, prestígio, produtividade, mobilidade profissional, responsabilidade social, status, remuneração, promoção social, estabilidade profissional e estilo de vida, em ordem de classificação estabelecida pelos respondentes do questionário. Todos os 19 fatores foram muito bem avaliados. O fator que foi mais bem avaliado pelos egressos - Respeitabilidade e reconhecimento acadêmico/profissional - atingiu 1111 pontos (de 1320 possíveis: 10 x 132 respondentes), representando, assim, 84,2\% da pontuação possível. Estilo de vida, fator que sofreu a pior avaliação, ainda assim, atingiu 830 pontos, ou seja, bem mais da metade dos pontos disponíveis.

O que se conclui é que as várias motivações declaradas pelos egressos para ingressar no doutoramento se materializaram em suas vidas acadêmico/profissionais, qualquer que seja o nome pelo qual sejam reconhecidas e declaradas.

Uma constatação crítica é que, mesmo sendo poucos os possuidores do título de doutor em Ciências Contábeis, quando confrontados com o grande número de cursos de graduação em Ciências Contábeis, 159 titulados até 31/12/2005, mais de 30,0\%, mantém a principal atividade remunerada vinculada ao mercado. Se considerarmos que o objetivo principal do doutoramento é a qualificação para a docência e a formação de pesquisadores, este não vem cumprindo integralmente seu papel. Entende-se que o alto percentual de doutores que mantém como principal atividade remunerada o mercado é motivado principalmente pelos ganhos monetários, visto que os dados da pesquisa mostraram que aqueles que estão no mercado percebem mais que os vinculados à academia.

Outro agravante é a idade com que se titulam, em torno de 42 anos, altíssima para os padrões mundiais, apesar de não tanto para os padrões nacionais; mas, sem dúvida, importante fator limitante da criatividade e da disposição. Além de ir contra os preceitos da teoria do capital humano: jovens estariam mais dispostos a renunciar a ganhos para adquirir mais educação.

O doutoramento em Ciências Contábeis é curso essencialmente masculino, quase 85,0\% dos doutores pertencem a esse gênero. Entre terminar a graduação, com mais de 24 anos e iniciar o doutorado, transcorrem aproximadamente 14 anos. O tempo gasto para a titulação vem diminuindo ao longo dos tempos. Nos anos 2000, os doutores levaram cerca de 3 anos e 10 meses para obter o título, mesmo tempo gasto para conclusão do seu mestrado. O egresso do Doutorado em Ciências Contábeis é, primordialmente, um egresso do Mestrado em Ciências Contábeis da FEA/USP. Cerca de 85,0\% daqueles doutores em Ciências Contábeis que são possuidores de um mestrado em Ciências Contábeis se titularam nesse mesmo programa. Conclui-se que o curso de Mestrado em Ciências Contábeis da FEA/USP é o maior insumo do curso de Doutorado em Ciências Contábeis da FEA/USP. A obtenção da titulação possibilitou, ainda, aos egressos da área, uma nítida mudança nas atividades desenvolvidas no momento de ingresso ao curso em relação à principal atividade remunerada atualmente desenvolvida. Ao ingressarem, mais de $50,0 \%$ as desenvolviam no mercado e, hoje, pouco mais de $30,0 \%$ o fazem.

Os resultados evidenciam que o Doutorado em Ciências Contábeis tem encontrado sua principal clientela entre homens casados que desenvolvem suas atividades no mercado, em grande parte oriundos de São Paulo e do próprio Programa de Pós-Graduação em Ciências Contábeis da FEA/USP, e que a maioria de seus egressos permanece em São Paulo, atuando na academia.

Quase 95,0\% dos doutores que possuem a principal atividade remunerada vinculada à academia declararam que suas atividades atuais envolvem pesquisa. Mais um ponto a ser observado é que uma 
das mais expressivas motivações alegadas pelos doutores para seu ingresso no doutorado foi a intenção em seguir ou aprimorar a carreira de pesquisador, mesmo entre os doutores que declararam possuir a principal atividade remunerada vinculada ao mercado. Por outro lado, o incentivo representado pela vontade em seguir ou aprimorar a carreira docente foi francamente seguido. Enquanto, no ingresso ao doutorado, menos da metade dos doutores em Ciências Contábeis mantinham como principal atividade remunerada atividades acadêmicas, na data de preenchimento do questionário pouco mais de 30,0\% dos doutores não desempenhavam esse tipo de atividade. O que precisa ser lembrado é o seguinte: no atual modelo de pós-graduação brasileiro, sequencial mestrado/doutorado, entendia-se que o mestrado é que deveria cumprir esse papel de formar professores. O doutorado deveria ser cursado por aqueles que desejassem dedicação à pesquisa. Não é o que se observa na área de Ciências Contábeis, visto que o doutorado ainda faz essa migração entre mercado e academia em percentuais bastante altos. Estaria havendo algum viés na seleção dos candidatos? Seria um ponto a ser investigado.

Outra motivação que conduziu os respondentes ao doutorado foi a obtenção de melhor nível de renda. E nesse ponto, alcançaram pleno êxito. Os efeitos da titulação sobre os rendimentos são bastante acentuados. Enquanto quase metade dos egressos declarou receber uma remuneração de até R\$ 5.000,00 quando ingressou no curso, esse percentual atinge menos de 7,0\% quando declarada a remuneração atual. Os que percebiam acima de $\mathrm{R} \$ 15.000,00$ não atingiam 11,0\% no ingresso. Atualmente, esse percentual está perto dos $40,0 \%$. Mais de $60,0 \%$ dos que declararam receber remuneração acima de $\mathrm{R} \$ 15.000,00$ desenvolvem sua principal atividade remunerada no mercado.

Os egressos demonstram grande satisfação quanto às contribuições do Doutorado em Ciências Contábeis para as atividades que desenvolvem atualmente, dentro do escopo avaliado pela pesquisa. Quanto à formação teórica e à atualização dos conhecimentos proporcionados pelo curso, o percentual daqueles que julgam estar contribuindo muito é bastante próximo, tanto para os que desenvolvem sua principal atividade remunerada na academia quanto para os que a desenvolvem no mercado. Conforme esperado, as contribuições de experiência em pesquisa dependem da atividade desenvolvida atualmente pelo egresso. Foi mais bem avaliada por aqueles vinculados à academia e, segundo declararam, desenvolvendo essas atividades.

Os contatos acadêmicos ou profissionais obtidos durante o doutorado, embora de certa importância, não são o principal produto do curso e trouxeram menores contribuições na percepção dos titulados atuantes no mercado.

Depreende-se dos achados da pesquisa que os resultados podem estar refletindo a escassez de doutores em Ciências Contábeis. Torna-se, então, imperiosa a implantação de programas de doutoramento, para tornar a oferta desses profissionais mais elástica. Recomenda-se, no entanto, que não se descuide do controle da qualidade da educação fornecida, que é uma possível implicação para períodos de expansão. Isso pode ser comprovado pelos resultados divulgados pelo Ministério da Educação para o primeiro Exame Nacional de Desempenho de Estudantes (Enade), realizado no país, em substituição ao provão.

A expansão no ensino superior teve como consequência uma queda acentuada na qualidade da educação. Esse problema na qualidade é tão sério que poderia até mesmo anular a relação positiva existente entre educação e renda e os retornos sociais já amplamente comprovados, destruindo as boas evidências existentes de que o Doutorado em Ciências Contábeis influencia positivamente o desenvolvimento dos egressos e da sociedade.

Artigo recebido em 19.11.2008. Aprovado em 06.07.2009. 


\section{REFERÊNCIAS BIBLIOGRÁFICAS}

Baptiste, I. (2001). Educating lone wolves: pedagogical implications of human capital theory. Adult Education Quartely, 51(3), 184-201.

Baruch, Y., \& Peirperl, M. (2000). The impact of an MBA on graduate careers. Human Resource Management Journal, 10(2), 69-90.

Becker, G. S. (1962). Investment in human capital: a theoretical analysis. The Journal of Political Economy, Part 2: Investment in human beings, 70(5), 9-49.

Blaug, M. (1965). The rate of return on investment in education in Great Britain. The Manchester School, 33(3), 205-251.

Blaug, M. (1975). Introdução à economia da educação. (Leonel Vallandro \& Volnei Alves Corrêa, Trad.). Porto Alegre: Globo. (Obra original publicada em 1970).

Blaug, M. (1976). The empirical status of human capital theory: a slighthy jaundiced survey. Journal of Economic Literature, 14(3), 827-855.

Braga, M. M. (2002). Mestres e doutores em Bioquímica. In J. Velloso (Org.), A pós-graduação no Brasil: formação e trabalho de mestres e doutores no país (pp. 125-176). Brasília: Fundação Coordenação de Aperfeiçoamento de Pessoal de Nível Superior.

Braga, M. M., \& Azevedo, S. de (2002). Mestres e doutores em Química. In J. Velloso (Org.), A pósgraduação no Brasil: formação e trabalho de mestres e doutores no país (pp. 305-342). Brasília: Fundação Coordenação de Aperfeiçoamento de Pessoal de Nível Superior.

Carcello, J. V., Hermanson, D. R., Hermanson, R. H., \& Turner, D. H. (1994). Doctoral study in accounting: costs and financial support. Issues in Accounting Education, 9(2), pp. 219-230.

Cave, M., \& Weale, M. (1996). Higher education: expansion and reform. In T. Jenkinson (Ed.). Readings in microeconomics (pp. 229-242). New York: Oxford University Press.

Coordenação de Aperfeiçoamento de Pessoal de Nível Superior. (2004). Plano Nacional de PósGraduação (PNPG) - 2005-2010. Brasília. Recuperado em 25 janeiro, 2006 de http://www.capes.gov.br/capes/portal/conteudo/10/PNPG.htm

Cunha, J. V. A. (2007). Doutores em Ciências Contábeis da FEA/USP: análise sob a óptica da teoria do capital humano. Tese de Doutorado em Ciências Contábeis, Faculdade de Economia e Contabilidade da Universidade de São Paulo, São Paulo, SP, Brasil.

Dugan, M. K., Grady, W. R., Payn, B., \& Johnson, T. R. (1999). The benefits of an MBA: a comparison of graduates and non-graduates. Selections, 15(2), 18-24. Recuperado em 07 junho, 2006, de http://www.gmac.com/publications/rad061CC.pdf

Farrell, P., \& Fuchs, V. R. (1982). Schooling and health: the cigarette connection. Journal of Health Economics, 1(3), 217-230.

Fernandes, R., \& Narita, R. D. T. (2001). Instrução superior e mercado de trabalho no Brasil. Revista de Economia Aplicada, 5(1), 7-32.

Fitzsimons, P. (1999). Human capital theory and education. University of Auckland. Encyclopedia of Philosophy of Education. Recuperado em 16 junho, 2006, de http://www.vusst.hr/ENCYCLOPAEDIA/humancapital.htm 
Frezatti, F., \& Kassai, S. (2003, outubro). Estudo do impacto de um curso de MBA em Controladoria na evolução de seus egressos. Revista Contabilidade \& Finanças - USP, Edição Comemorativa, 54-65.

Gall, M. D., Gall, J. P., \& Borg, W. R. (2007). Educational research: an introduction (8th. ed.). Boston: Person/Allyn and Bacon.

Gonzaga, G., \& Soares, R. R. (1999). Determinação de salários no Brasil: dualidade ou nãolinearidade no retorno à educação? Revista de Econometria, 19(2), 367-404.

Hasselback, J. R. (2007). Accounting doctoral programs. Recuperado em 03 fevereiro, 2007, de http://www.jrhasselback.com/AtgDoct/AtgDoctProg.html

Haveman R. H., \& Wolfe, B. L. (1984). Schooling and economic well-being: the role of nonmarket effects. Journal of Human Resources, 19(3), 377-407.

Hunton, J. E., Stone, D. N., \& Wier, B. (2005). Does graduate business education contribute to professional accounting success? Accounting Horizons, 19(2), 85-100.

Instituto Nacional de Estudos e Pesquisas Educacionais Anísio Teixeira. (2004). EdutaBrasil. Sistema de estatísticas educacionais. Recuperado em 26/06/2007 de http://www.edudatabrasil.inep.gov.br/

Ioschpe, G. (2004). A ignorância custa um mundo: o valor da educação no desenvolvimento do Brasil. São Paulo: Francis.

Ivo, A. B. L., \& Carvalho, I. M. M. (2002). Caminhos cruzados: entre mercado e academia. Trajetória de mestres e doutores em engenharia elétrica. In J. Velloso (Org.), A pós-graduação no Brasil: formação e trabalho de mestres e doutores no país (pp. 257-282). Brasília: Fundação Coordenação de Aperfeiçoamento de Pessoal de Nível Superior.

Johnson, H. G. (1964). Towards a generalized capital accumulation approach to economic development. OECD Study Group in the Economics of Education The Residual Factor and Economic Growth, Paris, França.

Lam, D., \& Levison, D. (1990). Idade, experiência, escolaridade e diferença de renda: EUA e Brasil. Pesquisa e Planejamento Econômico, 20(2), 219-256.

Langoni, C. G. (1973). Distribuição da renda e desenvolvimento econômico do Brasil. Rio de Janeiro: Expressão e Cultura.

Lochner, L., \& Moretti, E. (2001). The effect of education on crime: evidence from prison inmates, arrests and self-reports [Working Paper $N^{\circ}$ 8605]. National Bureau of Economic Research, Cambridge, MA, Recuperado em 05 abril, 2006, de http://www.nber.org/papers/8605

Machado, M. R. (2003). O resultado econômico-financeiro proporcionado aos profissionais mediante a conclusão de cursos de pós-graduação lato sensu em Contabilidade, 1988-2001. Dissertação de Mestrado em Ciências Contábeis, Programa Multiinstitucional e Inter-Regional de PósGraduação em Ciências Contábeis, Universidade de Brasília, Universidade Federal da Paraíba, Universidade Federal de Pernambuco, Universidade Federal do Rio Grande do Norte, João Pessoa, PE, Brasil.

Mangematin, V. (2000). Job market: Professional trajectories and incentive during the Ph.D. Research Policy, 29(6), 741-756.

Martins, G. A. de (2000). Manual para elaboração de monografias e dissertações (2a ed.). São Paulo: Atlas. 
Matos, B. P., Balbachevsky, E., Sampaio, H., \& Velloso, J. (2002). Formação acadêmica e mercado de trabalho: os destinos profissionais de mestres e doutores em Administração. In J. Velloso (Org.), A pós-graduação no Brasil: formação e trabalho de mestres e doutores no país (pp. 61-100). Brasília: Fundação Coordenação de Aperfeiçoamento de Pessoal de Nível Superior.

Menezes-Filho, N. A. (2001). A evolução da educação no Brasil e seu impacto no mercado de trabalho. Recuperado em 15 março, 2006 de http://www.ifb.com.br/arquivos/artigo_naercio.pdf

Moretti, E. (2002). Estimating the social return to higher education: evidence from longitudional and repeated cross-sectional data [Working Paper $\mathrm{N}^{\circ}$ 9108]. National Bureau of Economic Research, Cambridge, MA. Recuperado em 13 maio, 2006, de http://www.nber.org/papers/9108

Newell, G., Langsam, S., \& Kreuze, J. (1996). Accounting faculty profiles: demographics and perceptions of academia. Journal of Education for Business, 72(2), 87-93.

Oliveira, M. das G. C. de, \& Weber, S. (2002). Mestres e doutores em agronomia: um estudo sobre egressos (pp. 101-124). In J. Velloso (Org.), A pós-graduação no Brasil: formação e trabalho de mestres e doutores no país. Brasília: Fundação Coordenação de Aperfeiçoamento de Pessoal de Nível Superior.

Oliven, A. C., \& Neves, C. E. B. (2002). Mestres e doutores em clínica médica (pp. 177-202).. In J. Velloso (Org.), A pós-graduação no Brasil: formação e trabalho de mestres e doutores no país. Brasília: Fundação Coordenação de Aperfeiçoamento de Pessoal de Nível Superior.

Psacharopoulos, G., \& Patrinos, H. A. (2002). Returns to investment in education: a further update [Working Paper, No 2881]. World Bank Policy Research, Washington, DC. Recuperado em 12 julho, 2006, de http://www-wds.worldbank.org/servlet/WDSContentServer/WDSP/IB/2002/09/27/ 000094946_02091705491654/Rendered/PDF/multi0page.pdf

Ramos, L. A. (1991). Educação, desigualdade de renda e ciclo econômico no Brasil. Pesquisa e Planejamento Econômico, 21(3), 559-574.

Rauch, J. E. (1993). Productivity gains from geographic concentration of human capital: evidence from the cities. Journal of Urban Economics, 34(3), 380-400.

Sampaio, H., \& Velloso, J. (2002). Mestres e doutores em engenharia civil: da empresa à academia? (pp. 203-256). In J. Velloso (Org.), A pós-graduação no Brasil: formação e trabalho de mestres e doutores no país. Brasília: Fundação Coordenação de Aperfeiçoamento de Pessoal de Nível Superior).

Schuller, T., \& Field, J. (1998). Social capital, human capital and the learning society. International Journal of Lifelong Education, 17(4), 226-235.

Schultz, T. W. (1960). Capital formation by education. The Journal of Political Economy, 68(6), 571-583.

Schultz, T. W. (1961). Investment in human capital. The American Economic Review, 51(1), 1-17.

Schultz, T. W. (1973). O capital humano: investimento em educação e pesquisa. (Marco Aurélio de Moura Matos, Trad.). Rio de Janeiro: Zahar Editores. (Obra original publicada em 1968).

Senna, J. (1976). Escolaridade, experiência no trabalho e salários no Brasil. Revista Brasileira de Economia, Rio de Janeiro, 30 (2).

Sobel, I. (1978). The human capital revolution in economic development: its current history and status. Comparative Education Review, 22(2), 278-308.

Spagnolo, F., \& Günther, H. (1986). 20 anos de pós-graduação: o que fazem nossos mestres e doutores? Uma visão geral. Ciência e Cultura, 38(10), 1643-1662. 
Stamatakis, D., \& Petrakis, P. E. (2005). Human capital convergence: a cross country empirical investigation. The Business Review, 3(2), 310-321.

Stirati, A., \& Cesaratto, S. (1995). The italian Ph.D. ten years on: educational scientific and occupational outcomes. Higher Education, 30(1), 37-61.

Stuart, D. G., Dattero, R., \& Quan, J. J. (2004). The effect of age on computer programmer wages. Journal of Computer Information Systems, 45(1), 57-68.

Tannen, M. B. (1991). New estimates of the returns to schooling in Brazil. Economics of Education Review, 10 (2), 123-135.

Velloso, J. (Org.). (2002). A pós-graduação no Brasil: formação e trabalho de mestres e doutores no país. Brasília: Fundação Coordenação de Aperfeiçoamento de Pessoal de Nível Superior.

Velloso, J., \& Velho, L. (2001). Mestrandos e doutorandos no país: trajetórias de formação. Brasília: Fundação Coordenação de Aperfeiçoamento de Pessoal de Nível Superior.

Walsh, J. R. (1935). Capital concept applied to man. Quarterly Journal of Economics, 49(1), 255-285. 